\title{
OClO and BrO observations in the volcanic plume of Mt. Etna - implications on the chemistry of chlorine and bromine species in volcanic plumes
}

\author{
J. Gliß ${ }^{1,2,3}$, N. Bobrowski ${ }^{2}$, L. Vogel ${ }^{4,2}$, D. Pöhler ${ }^{2}$, and U. Platt ${ }^{2}$ \\ ${ }^{1}$ Norwegian Institute for Air Research (NILU), Kjeller, Norway \\ ${ }^{2}$ Institute of Environmental Physics, Heidelberg, Germany \\ ${ }^{3}$ Faculty of Mathematics and Natural Sciences, Department of Physics, University of Oslo (UiO), Oslo, Norway \\ ${ }^{4}$ Earth Observation Science, Space Research Centre, Department of Physics and Astronomy, \\ University of Leicester, United Kingdom
}

Correspondence to: J. Gliß (jonas.gliss@ nilu.no)

Received: 20 August 2014 - Published in Atmos. Chem. Phys. Discuss.: 1 October 2014

Revised: 15 April 2015 - Accepted: 16 April 2015 - Published: 26 May 2015

\begin{abstract}
Spatial and temporal profiles of chlorine dioxide $(\mathrm{OClO})$, bromine monoxide $(\mathrm{BrO})$ and sulfur dioxide $\left(\mathrm{SO}_{2}\right)$ of the volcanic plume at Mt. Etna, Italy, were investigated in September 2012 using Multi-Axis Differential Optical Absorption Spectroscopy (MAX-DOAS). OClO was detected in 119 individual measurements covering plume ages up to $6 \mathrm{~min}$. $\mathrm{BrO}$ could be detected in 452 spectra up to $23 \mathrm{~min}$ downwind. The retrieved slant column densities (SCDs) reached maximum values of $2.0 \times 10^{14}$ molecules $\mathrm{cm}^{-2}$ $(\mathrm{OClO})$ and $1.1 \times 10^{15}$ molecules $\mathrm{cm}^{-2}(\mathrm{BrO})$.

Mean mixing ratios of $\mathrm{BrO}$ and $\mathrm{OClO}$ were estimated assuming a circular plume cross section. Furthermore, $\mathrm{ClO}$ mixing ratios were derived directly from the $\mathrm{BrO}$ and $\mathrm{OClO}$ SCDs. Average abundances of $\overline{\mathrm{BrO}}=1.35 \mathrm{ppb}, \overline{\mathrm{OClO}}=$ $300 \mathrm{ppt}$ and $\overline{\mathrm{ClO}}=139 \mathrm{ppt}$ were found in the young plume (plume age $\tau<4 \mathrm{~min}$ ) with peak values of $2.7 \mathrm{ppb}(\mathrm{BrO})$, $600 \mathrm{ppt}(\mathrm{OClO})$ and $235 \mathrm{ppt}(\mathrm{ClO})$ respectively.

The chemical evolution of $\mathrm{BrO}$ and $\mathrm{OClO}$ in the plume was investigated in great detail by analysing the $\mathrm{OClO} / \mathrm{SO}_{2}$ and $\mathrm{BrO} / \mathrm{SO}_{2}$ ratios as a function of plume age $\tau$. A marked increase of both ratios was observed in the young plume $(\tau<142 \mathrm{~s})$ and a levelling off at larger plume ages showing mean $\mathrm{SO}_{2}$ ratios of $3.17 \times 10^{-5}\left(\mathrm{OClO} / \mathrm{SO}_{2}\right)$ and $1.65 \times$ $10^{-4}\left(\mathrm{BrO} / \mathrm{SO}_{2}\right)$. OClO was less abundant in the plume compared to $\mathrm{BrO}$ with a mean $\mathrm{OClO} / \mathrm{BrO}$ ratio of 0.16 at plume ages exceeding $3 \mathrm{~min}$.
\end{abstract}

A measurement performed in the early morning at low solar radiances revealed $\mathrm{BrO} / \mathrm{SO}_{2}$ and $\mathrm{OClO} / \mathrm{SO}_{2}$ ratios increasing with time. This observation substantiates the importance of photochemistry regarding the formation of $\mathrm{BrO}$ and $\mathrm{OClO}$ in volcanic plumes.

These findings support the current understanding of the underlying chemistry, namely, that $\mathrm{BrO}$ is formed in an autocatalytic, heterogeneous reaction mechanism (in literature often referred to as "bromine explosion") and that $\mathrm{OClO}$ is formed in the reaction of $\mathrm{ClO}$ with $\mathrm{BrO}$.

These new findings, especially the very detailed observation of the $\mathrm{BrO}$ and $\mathrm{OClO}$ formation in the young plume, were used to infer the prevailing $\mathrm{Cl}$-atom concentrations in the plume. Relatively small values ranging from $[\mathrm{Cl}]=$ $2.5 \times 10^{6} \mathrm{~cm}^{-3}$ (assuming $80 \mathrm{ppb}$ background $\mathrm{O}_{3}$ ) to $[\mathrm{Cl}]=$ $2.0 \times 10^{8} \mathrm{~cm}^{-3}$ (at $1 \mathrm{ppb} \mathrm{O}_{3}$ ) were calculated at plume ages of about $2 \mathrm{~min}$. Based on these $\mathrm{Cl}$ abundances, a potential chlorine-induced - depletion of tropospheric methane $\left(\mathrm{CH}_{4}\right)$ in the plume was investigated. $\mathrm{CH}_{4}$ lifetimes between $14 \mathrm{~h}$ (at $1 \mathrm{ppb} \mathrm{O}_{3}$ ) and 47 days (at $80 \mathrm{ppb} \mathrm{O}_{3}$ ) were derived. While these lifetimes are considerably shorter than the atmospheric lifetime of $\mathrm{CH}_{4}$, the impact of gaseous chlorine on the $\mathrm{CH}_{4}$ budget in the plume environment should nevertheless be relatively small due to plume dispersion (decreasing $\mathrm{Cl}$ concentrations) and ongoing mixing of the plume with the surrounding atmosphere (replenishing $\mathrm{O}_{3}$ and $\mathrm{CH}_{4}$ ). 
In addition, all spectra were analysed for signatures of $\mathrm{IO}$, OIO and OBrO. None of these species could be detected. Upper limits for $\mathrm{IO} / \mathrm{SO}_{2}, \mathrm{OIO} / \mathrm{SO}_{2}$ and $\mathrm{OBrO} / \mathrm{SO}_{2}$ are $1.8 \times 10^{-6}, 2.0 \times 10^{-5}$ and $1.1 \times 10^{-5}$ respectively.

\section{Introduction}

In the past years, improved measurement techniques, especially remote sensing methods, gained importance for the study of the chemical composition of volcanic plumes.

In this study we present Multi-Axis Differential Optical Absorption Spectroscopy (MAX-DOAS) measurements (e.g. Hönninger et al., 2004) of the volcanic plume at Mt. Etna on Sicily, Italy, performed in September 2012. MAX-DOAS is an established method to simultaneously study a variety of chemical species in volcanic plumes by analysing scattered sunlight spectra. Furthermore, it is easily possible to monitor the volcanic emissions over a wide range of different plume ages, which is of particular importance for studies related to the chemical evolution of the emitted species. It is well known that volcanic gases can have significant impacts on atmosphere and climate both on local and global scales (e.g. acid rain, stratospheric sulfur aerosols; see e.g. Robock, 2000). Furthermore, the chemical composition of volcanic plumes - especially in the young plume - can give insights into the degassing behaviour of the magma and may even be related to the state of activity of the volcano (e.g. Donovan et al., 2014). In addition, the environment of volcanic plumes provides an unique possibility to study details of complex chemical reaction mechanisms related to atmospheric ozone/oxidant chemistry in the presence of reactive halogen species (RHS).

The focus of this article is with regard to the chemical evolution of volcanic halogens, especially on the formation of RHS (e.g. $\mathrm{BrO}, \mathrm{ClO}, \mathrm{OClO}$ ) from the primarily emitted species (e.g. $\mathrm{HCl}, \mathrm{HBr}$ ) and their evolution in the ageing plume. The scientific interest in volcanic RHS increased dramatically when large amounts of bromine monoxide $(\mathrm{BrO})$ were detected in the plume of Soufriére Hills volcano, Montserrat (Bobrowski et al., 2003). Today, we have only gained a rough understanding of the chemical processes involved in the RHS formation in volcanic plumes and possible dependencies due to the presence of other species (e.g. ozone or nitrogen oxides). Especially the conversion of the emitted $\mathrm{HCl}$ into reactive chlorine is still poorly understood. This is both due to a lack of measurement data and the complexity of the chemical processes involved.

\section{Halogens in volcanic plumes}

\subsection{Initial plume composition}

The main constituents of volcanic plumes are $\mathrm{H}_{2} \mathrm{O}, \mathrm{CO}_{2}$ and sulfur gases (dominated by $\mathrm{SO}_{2}, \mathrm{H}_{2} \mathrm{~S}$ ). Apart from these species, volcanoes also emit a certain amount of halogen species which are mainly released in the rather unreactive form of hydrogen halides such as $\mathrm{HCl}, \mathrm{HF}, \mathrm{HBr}, \mathrm{HI}$ (e.g. Carroll and Holloway, 1994; Francis et al., 1995; Gerlach, 2004) and which are largely dominated by the chlorine emissions (HCl). Pyle and Mather (2009) reviewed past measurements ( 1980-2008) of arc-related volcanic halogen emissions around the globe and found that $\mathrm{HCl}$ emissions contribute most with an estimated flux of $4.3( \pm 1) \mathrm{Tg} \mathrm{a}^{-1}$. $\mathrm{HBr}$ and $\mathrm{HI}$ emissions are orders of magnitude smaller with fluxes of 5-15 and $0.5-2 \mathrm{Gg} \mathrm{a}^{-1}$ respectively.

In the case of Mt. Etna, $\mathrm{SO}_{2} / \mathrm{HCl}$ ratios between 2 and 7 were found in past measurements (e.g. Francis et al., 1995; La Spina et al., 2010; Voigt et al., 2014). $\mathrm{SO}_{2}$ appears to dominate the total sulfur emissions of Etna with $\mathrm{SO}_{2} / \mathrm{H}_{2} \mathrm{~S}$ ratios of the order of $10^{1}-10^{3}$ (Jaeschke et al., 1982; Aiuppa et al., 2005).

A certain amount of the emitted hydrogen halides is converted into RHS, whereas the conversion from $\mathrm{HBr}$ into $\mathrm{BrO}$ appears to be much more efficient than the analogous reactions for volcanic chlorine. A key question related to these conversion mechanisms is the production of the halogen radicals (i.e. $\mathrm{Br}, \mathrm{Cl}, \mathrm{I}$ ) in the plume. Once these are provided, oxidised halogens such as $\mathrm{BrO}$ and $\mathrm{ClO}$ are formed in reaction with ozone $\left(\mathrm{O}_{3}\right)$.

\subsection{Formation of RHS in the plume - the bromine explosion}

A certain amount of RHS (e.g. Cl, Br) can be produced in the hot initial plume via high-temperature oxidative dissociation processes as suggested by model studies (e.g. Gerlach, 2004; Martin et al., 2006). Furthermore, Br can be formed via the reaction of $\mathrm{HBr}$ with $\mathrm{OH}$ in the very young plume (Roberts et al., 2009). However, the corresponding amounts are by far too small to explain the $\mathrm{BrO}$ amounts observed. In fact, the largest part of $\mathrm{BrO}$ is formed in atmospheric reactions, including the photolysis of $\mathrm{Br}_{2}$ and $\mathrm{BrCl}$ (e.g. Oppenheimer et al., 2006; Bobrowski et al., 2007; Kern et al., 2009). This is further supported by direct observations showing a strong increase of the $\mathrm{BrO}$ levels in the young plume (e.g. Bobrowski et al., 2007; Bobrowski and Giuffrida, 2012) and the virtual absence during night-time (Kern et al., 2009). Nowadays, the underlying chemical reaction processes of the $\mathrm{BrO}$ formation in the young plume are mostly understood and likely driven by a heterogeneous and partly auto-catalytic reaction mechanism often referred to as "bromine explosion" (e.g. Lehrer et al., 1997; Wennberg, 1999), which includes the following reactions (note that the subscript "aq" denotes species in the 
aqueous phase on particles).

$$
\begin{aligned}
& \mathrm{BrO}+\mathrm{HO}_{2} \rightarrow \mathrm{HOBr}_{\text {gas }}+\mathrm{O}_{2} \\
& \mathrm{HOBr}_{\text {gas }} \rightarrow \mathrm{HOBr}_{\text {aq }} \\
& \mathrm{HBr}_{\text {gas }} \rightarrow \mathrm{HBr}_{\text {aq }} \rightarrow \mathrm{Br}_{\text {aq }}^{-}+\mathrm{H}_{\mathrm{aq}}^{+} \\
& \mathrm{HOBr}_{\text {aq }}+\mathrm{Br}_{\text {aq }}^{-}+\mathrm{H}_{\mathrm{aq}}^{+} \rightarrow \mathrm{Br}_{2, \text { gas }}+\mathrm{H}_{2} \mathrm{O} \\
& \mathrm{Br}_{2, \text { gas }}+h v \rightarrow 2 \mathrm{Br} \\
& 2 \mathrm{Br}+2 \mathrm{O}_{3} \rightarrow 2 \mathrm{BrO}+2 \mathrm{O}_{2}
\end{aligned}
$$

The "bromine explosion" encompasses the uptake of hypobromous acid ( $\mathrm{HOBr}$ ) from the gas into the aqueous phase. After the reaction of $\mathrm{HOBr}$ with bromide, $\mathrm{Br}_{2}$ is released into the gas phase where it is rapidly photolysed, forming $\mathrm{BrO}$ in reaction with $\mathrm{O}_{3}$. Once formed, the self-reaction of $\mathrm{BrO}$ induces a catalytic destruction of $\mathrm{O}_{3}$. Noteworthy in this context are the similarities to observations of bromine emissions in polar regions (e.g. Barrie et al., 1988; Simpson et al., 2007). Measurements performed at Mt. Etna and Stromboli volcano (Aeolian islands, Italy) indicate that up to $11 \%$ of the total emitted bromine is converted into $\mathrm{BrO}$ already within the first 5 min downwind (Wittmer et al., 2014).

\subsection{Volcanic chlorine}

Potential formation processes of reactive chlorine species from the emitted $\mathrm{HCl}$ are still little studied. Apparently, the activation of chlorine is much weaker compared to bromine. This is indicated by the comparatively low $\mathrm{Cl}$ and $\mathrm{ClO}_{y}$ abundances we found (relative to the $\mathrm{BrO}$ ratios), indicating that less than $1 \%$ of the emitted $\mathrm{HCl}$ is converted into reactive chlorine $\left(\mathrm{ClO}_{y}\right)$ in the Etna plume. In other words, $\mathrm{ClO}_{y} / \mathrm{HCl}$ is much smaller than $\mathrm{BrO} / \mathrm{HBr}$. In our opinion this phenomenon is mainly due to the fact that $\mathrm{Br}$ oxidation (conversion of bromide to $\mathrm{Br}, \mathrm{BrO}$ ) is a self-amplifying process (the bromine explosion) while $\mathrm{Cl}$ oxidation has no such properties. The reason why $\mathrm{Br}$ "explodes" but $\mathrm{Cl}$ does not is due to the relatively fast reaction of $\mathrm{Cl}$ atoms with $\mathrm{CH}_{4}$ (Platt and Janssen, 1995; Platt, 2000). Moreover, the dissolved chloride ions are less reactive compared to bromide ions (see Reaction R4) (von Glasow et al., 2009). Thus, Cl release is rather likely to be a by-product of the bromine explosion via formation of $\mathrm{BrCl}$ in the reaction of $\mathrm{HOBr}$ with chloride. However, the efficiency of this chlorine release channel strongly depends on the $\mathrm{Cl}^{-} / \mathrm{Br}^{-}$ion ratio in the condensed phase (Fickert et al., 1999). A significant release of $\mathrm{BrCl}$ is only likely for $\mathrm{Cl}^{-} / \mathrm{Br}^{-}$ratios exceeding $10^{4}$; for instance a $\mathrm{Cl}^{-} / \mathrm{Br}^{-}$ratio of $2 \times 10^{4}$ would yield a release of $50 \% \mathrm{BrCl}$ and $50 \% \mathrm{Br}_{2}$. Direct sampling measurements at Mt. Etna revealed $\mathrm{Cl}^{-} / \mathrm{Br}^{-}$ratios of the order of $10^{2}$ (Martin et al., 2008) up to $10^{3}$ (Wittmer et al., 2014). For these values the $\mathrm{HOBr}$ uptake yields a release of more than $90 \% \mathrm{Br}_{2}$. Note that this favoured $\mathrm{Br}_{2}$ release is probably even enhanced in volcanic plumes due to the acid environment (low $\mathrm{pH}$ in the aerosol, for details see Fickert et al., 1999, i.e. the pH dependency of the discussed mechanisms). To our knowledge, there are no measurements indicating $\mathrm{Cl}^{-} / \mathrm{Br}^{-}$ratios of the order of $10^{4}$ or larger at Mt. Etna. Hence, a significant $\mathrm{BrCl}$ release due to the $\mathrm{HOBr}$ uptake is relatively unlikely in the case of Mt. Etna.

Measurements of reactive chlorine species in volcanic plumes are still rare. Thus, the underlying chemistry is only partly understood and still bears large uncertainties, especially regarding the question of possible abundances of $\mathrm{Cl}$ atoms in the gaseous phase and the corresponding release mechanisms. However, once $\mathrm{Cl}$ atoms are provided, $\mathrm{ClO}$ is formed in the reaction with $\mathrm{O}_{3}$ and $\mathrm{OClO}$ is then formed in the reaction of $\mathrm{ClO}$ with $\mathrm{BrO}$ :

$\mathrm{BrO}+\mathrm{ClO} \rightarrow \mathrm{OClO}+\mathrm{Br}$.

The corresponding reaction rate coefficient is $k_{7}=6 \times$ $10^{-12} \mathrm{~cm}^{3} \mathrm{~s}^{-1}$ (at $298 \mathrm{~K}$; Sander et al., 2006). Further possible reaction channels for the $\mathrm{OClO}$ formation are orders of magnitude slower (e.g. $\mathrm{ClO}+\mathrm{O}_{3}, \mathrm{ClO}+\mathrm{ClO}$; Sander et al., 2006) and were not considered within this study. The main daytime sink of $\mathrm{OClO}$ is its photolysis:

$\mathrm{OClO}+h v \stackrel{J}{\rightarrow} \mathrm{ClO}+\mathrm{O} \quad J \approx 6 \times 10^{-2} \mathrm{~s}^{-1}$.

Both Bobrowski et al. (2007) and General et al. (2015) detected $\mathrm{OClO}$ in the plume of Mt. Etna. The corresponding $\mathrm{OClO} / \mathrm{SO}_{2}$ ratios were between 3 and $6 \times 10^{-5}$ (for spectra related to the plume centre). Simultaneous $\mathrm{BrO}$ measurements indicate an $\mathrm{OClO} / \mathrm{BrO}$ ratio of approximately 0.25 for Mt. Etna in both studies. Further detections of volcanic $\mathrm{OClO}$ are reduced to satellite measurements (PuyehueCordón Caulle volcano, Chile) after an eruption in 2011 (Theys et al., 2014) and most recently the detection of OClO in the plume of Soufriére Hills volcano (Montserrat) during a hiatus in 2011 (Donovan et al., 2014). In the latter study, comparatively large $\mathrm{OClO} / \mathrm{SO}_{2}$ ratios $\left(4-6 \times 10^{-4}\right)$ are reported as well as large $\mathrm{OClO} / \mathrm{BrO}$ ratios showing values up to 5 (i.e. about 20 times larger compared to Mt. Etna).

A key parameter for the OClO formation in volcanic plumes is the prevailing availability of $\mathrm{ClO}$ and $\mathrm{BrO}$ molecules. Previous studies reported relatively large amounts of volcanic $\mathrm{ClO}$ measured with passive DOAS instruments (Bobrowski et al., 2007; Lee et al., 2005). The corresponding $\mathrm{ClO} / \mathrm{SO}_{2}$ ratios were of the order of $5 \%$ hence, almost 3 orders of magnitude more $\mathrm{ClO}$ than $\mathrm{OClO}$. However, these measurements have to be treated cautiously due to difficulties and uncertainties in the DOAS evaluation of $\mathrm{ClO}$.

Furthermore, to our knowledge it has not yet been possible to reproduce these measurements in model studies (e.g. Bobrowski et al., 2007; von Glasow, 2010). Kern et al. (2009) investigated $\mathrm{ClO}$ and $\mathrm{OClO}$ abundances at the vent 
of Masaya Volcano (Nicaragua) using an active long-path DOAS instrument. They did not detect any of both species most likely due to the proximity of the measurement to the crater (i.e. early stage of the RHS formation). In addition, the halogen content of Masaya volcano is probably smaller compared to Mt. Etna (Pyle and Mather, 2009). While the $\mathrm{OClO} / \mathrm{ClO}$ ratios should typically be of the same order of magnitude in the case of Mt. Etna and Masaya (Kern et al., 2009; this study), this seems not to be the case for the Puyehue-Cordón Caulle eruption in 2011 which actually indicates a large excess of $\mathrm{ClO}$ compared to $\mathrm{OClO}$ and even $\mathrm{BrO}$ (Theys et al., 2014).

The focus of this article is the temporal and spatial evolution of RHS in volcanic plumes (especially $\mathrm{BrO}, \mathrm{ClO}, \mathrm{OClO}$ ) and potential impacts on the atmosphere in the vicinity of volcanic plumes. In particular, we use MAX-DOAS data to study the formation of $\mathrm{BrO}$ and $\mathrm{OClO}$ in the young plume in great detail and to infer typical formation times of these species (for the conditions at Mt. Etna in September 2012). We furthermore estimate mean plume abundances of $\mathrm{BrO}$, $\mathrm{ClO}$ and $\mathrm{OClO}$. These results are used to derive $\mathrm{Cl}$-atom concentrations in the plume in order to address the question of a potential - chlorine-induced - depletion of atmospheric methane $\left(\mathrm{CH}_{4}\right)$ in the plume environment.

\section{Methods and study area}

\subsection{Technical setup}

The MAX-DOAS instrument used in this study analyses the solar spectrum in the ultraviolet (UV) and the visible (VIS) ranges using two spectrographs (UV: Avantes AVA AvaBench-75-ULS2048x64; VIS: Avantes AVA AvaBench$75-$ ULS2048L) covering a spectral range of $292-578 \mathrm{~nm}$ (UV: $292.1-456.1 \mathrm{~nm}$; VIS: 434.7-577.8 nm). Scattered sunlight was collected using a small telescope consisting of a quartz lens $(f=100 \mathrm{~mm})$ which focuses incoming light onto an optical fibre bundle. The latter consists of seven individual fibres each with a diameter of $d=100 \mu \mathrm{m}$. Six of these were coupled into the UV spectrograph, while the seventh fibre was connected to the VIS spectrograph. The measured spectral resolution of both spectrographs was $\Delta \lambda_{\mathrm{UV}}=$ $0.51 \mathrm{~nm}$ and $\Delta \lambda_{\mathrm{VIS}}=0.39 \mathrm{~nm}$. A SCHOTT BG-3 filter was placed behind the entrance slit of the UV spectrograph to reduce stray light. The telescope was focused such that both spectrographs have approximately the same field of view (UV: $0.15^{\circ}$, VIS: $0.16^{\circ}$, full aperture angle). The optical benches of the spectrographs were thermally insulated and temperature stabilised using a Peltier element controlled by a Supercool PR-59 temperature controller. During the whole measurement campaign, both spectrographs were stabilised to a temperature of $T_{\text {meas }}=10^{\circ} \mathrm{C}$. The air-tight instrument box was mounted onto a tripod. Two motors (azimuth and elevation) allowed to control the viewing direction of the tele-

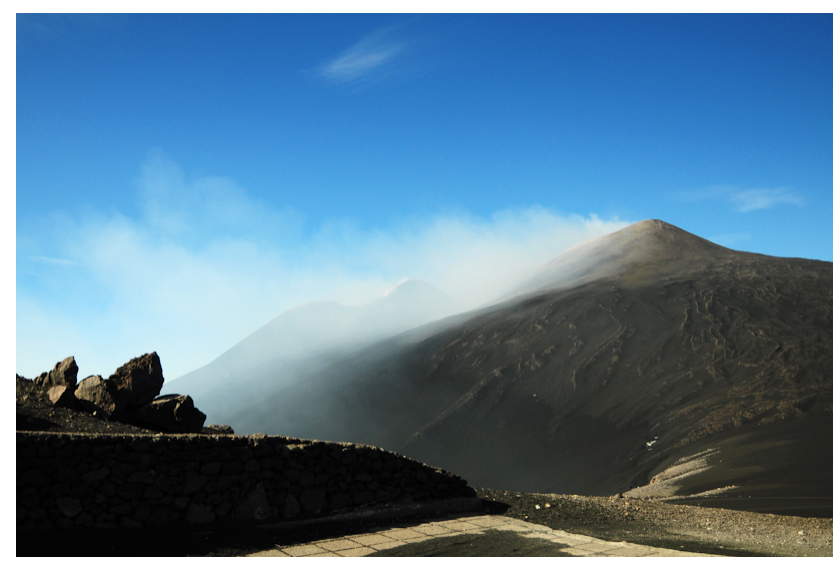

Figure 1. Photo of the volcanic plume on 13 September, 07:24 UTC (09:24 LT), from the Etna observatory. It shows a slightly condensed plume as it could be observed in most cases during the campaign.

scope, geo-locations were recorded using a GPS receiver. All hardware elements were remotely controlled using an embedded PC. The software MS-DOAS was used for data acquisition. MS-DOAS was developed by U. Frieß at the Institute of Environmental Physics in Heidelberg and is designed to control standard hardware components used in DOAS instruments (e.g. spectrographs, motors, temperature controller, GPS receiver). Furthermore, it includes a scripting feature making it easily possible to automatise measurement and scanning routines.

\subsection{Measurement location and data acquisition}

Mt. Etna is the largest and most active volcano in Europe and is situated in the eastern part of Sicily, an island south of the Italian mainland. The activity of Mt. Etna shows a distinct variability, including quiescent degassing periods as well as eruptive periods. During the measurement campaign in September 2012, Etna showed a stable quiescently degassing behaviour from the four active craters - north-east (NE), Bocca Nuova (BN), Voragine (VOR) and south-east (SE) crater - which are located in the summit region at an altitude of approximately $3300 \mathrm{ma}$ a.s.l. The first 3 days of the campaign (11-13 September 2012) took place at the Etna observatory (Pizzi Deneri) which is located approximately $2.5 \mathrm{~km}$ north-east of the active summit at an altitude of $2800 \mathrm{~m}$. Figure 1 shows a photo of the volcano and the emission plumes from the different craters. The photo was taken from the observatory and shows the NE crater (right) and the SE crater (faint in the background) on 13 September at 07:24 UTC. The plume was slightly condensed (see Fig. 1) during most of the measurements performed in September 2012 and showed no visible indications of any ash emissions. In Fig. 2, all measurement locations of the campaign (11-26 September 2012) are indicated. One of the main objectives of this study was to investigate the temporal evolution of oxidised halogens in 


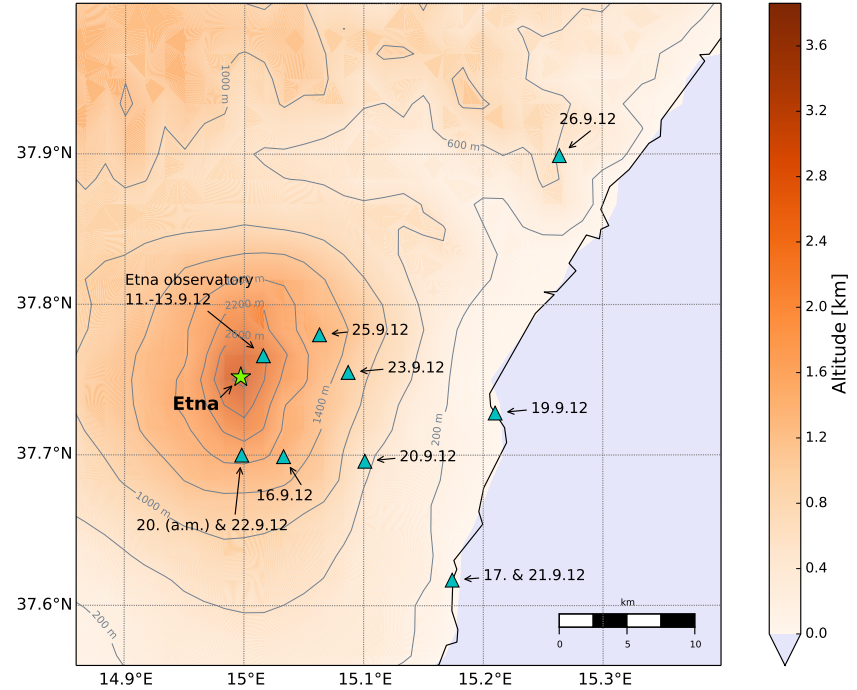

Figure 2. Measurement locations of the Etna campaign are indicated by blue triangles. The summit region with the four active craters (NE, BN, VOR and SE) is indicated by a green star.

the volcanic plume. Therefore, the measurements were performed at different locations in order to cover a large variety of different plume ages in the spectra.

\subsection{Plume scanning routines}

Three different plume scanning routines ("scans") were performed in order to study the chemical variability of the measured species in the volcanic plume (see sketch in Fig. 3). One "scan" typically consists of a set of plume spectra plus a subsequently recorded solar reference spectrum with the telescope pointing into a volcanic gas free atmosphere (for details see Sect. 3.4).

\subsubsection{Plume evolution scans}

The purpose of "plume evolution scans" is to study the chemical evolution of the measured species as a function of the plume age. The spectra are therefore recorded at different plume ages along the plume propagation direction (typically in the centre of the plume, see Fig. 3a).

\subsubsection{Plume cross-section scans}

"Plume cross-section scans" are performed perpendicular to the plume propagation axis in order to study chemical variations between the centre and the edges of the plume (Fig. 3b).

\subsubsection{Point measurements}

A certain number of spectra are taken at a fixed point in the plume without changing the viewing direction of the telescope. This measurement type is suited for the analysis of temporal variations in the plume composition (Fig. 3c).

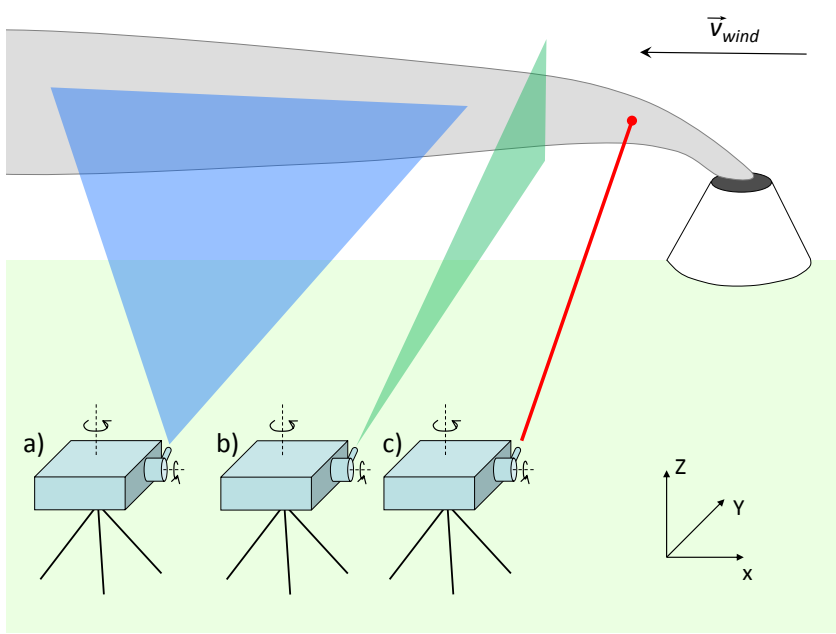

Figure 3. Sketch of the scanning routines: plume evolution scans (a, blue) scan stepwise along the plume propagation axis whereas plume cross-section scans (b, green) scan perpendicular to it. Point measurements (c, red) are performed at one spot in the plume without changing the telescope's viewing direction.

\subsection{Data acquisition and DOAS evaluation}

The spectra were analysed using the software package DOASIS (v. 3.2.4422, Kraus, 2006). Details on the scanning routines can be found in Sect. 3.3. In order to improve the detection sensitivity, several hundred up to 1500 individual spectra were co-added for the DOAS analysis. A standard DOAS fit (see Platt and Stutz, 2008) was performed for the UV and VIS spectra in order to retrieve slant column densities (SCDs) of the chemical species in the plume (in this study mainly: $\left.\mathrm{OClO}, \mathrm{BrO}, \mathrm{SO}_{2}, \mathrm{IO}, \mathrm{OBrO}, \mathrm{OIO}\right)$. A Fraunhofer reference spectrum (FRS, $I_{0}(\lambda)$ ) was included in the fitting routines to account for solar absorption lines in the spectra (Fraunhofer lines) and atmospheric background absorption. The FRS was recorded with the telescope pointing in the direction of a volcanic gas-free atmosphere and close in time to the corresponding plume spectra (usually subsequently to each scan). The latter is important to keep potential additional stratospheric signals at a minimum (for details see Sect. 3.9). Each potential FRS was pre-evaluated regarding its $\mathrm{SO}_{2}$ content using a literature solar background spectrum as FRS (Chance and Kurucz, 2010) which was convolved with the instrumental line spread function (LSF). Only FRS candidates showing $\mathrm{SO}_{2} \mathrm{SCDs}\left(\mathrm{S}_{\mathrm{SO}_{2}}\right)$ smaller than $S_{\mathrm{SO}_{2} \text {,FRS }}<5 \times 10^{16}$ molecules $\mathrm{cm}^{-2}$ were used as FRS.

In the following, the implemented steps to retrieve the SCDs from the raw spectra are described. Further details to individual topics regarding the data evaluation can be found in Appendix A.

Prior to the DOAS evaluation, all FRS and plume spectra were corrected for electronic offset and dark current. Two ring spectra $(R, R 4)$ were included into the fitting routine 

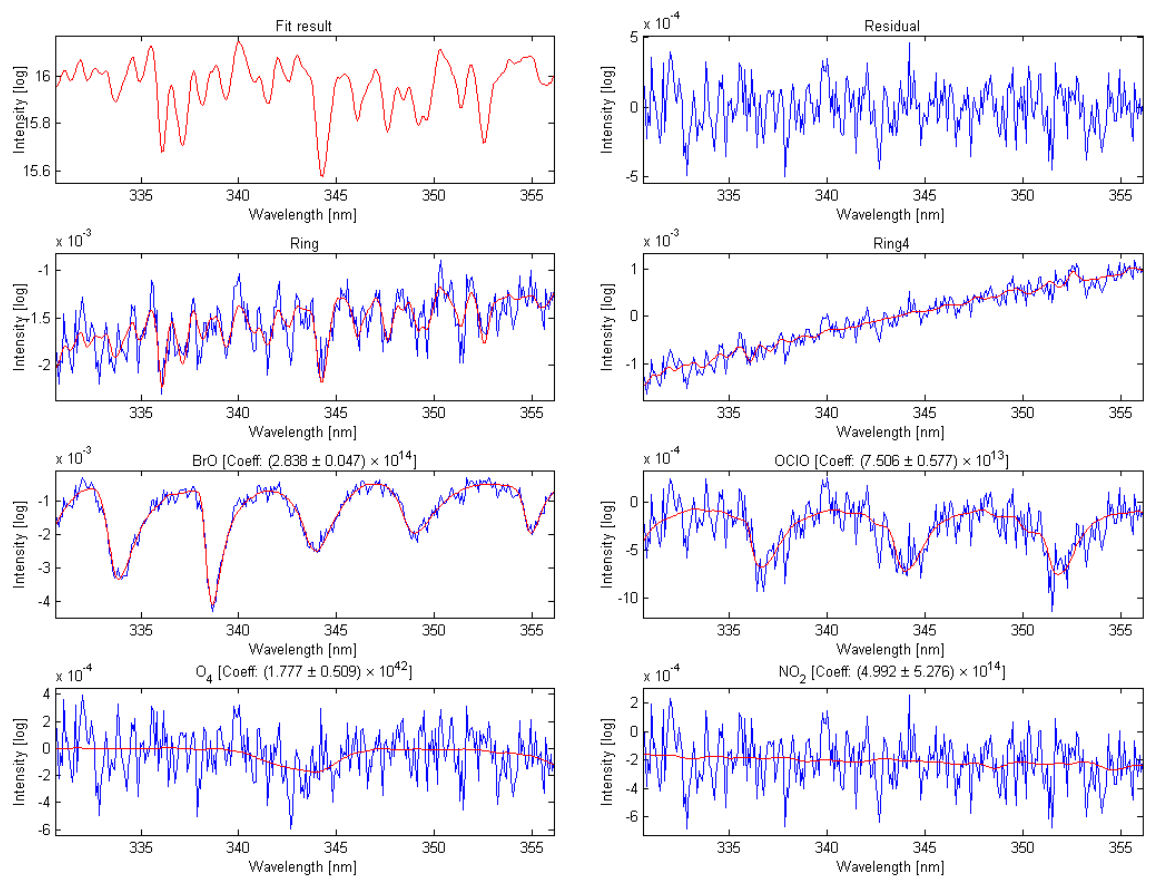
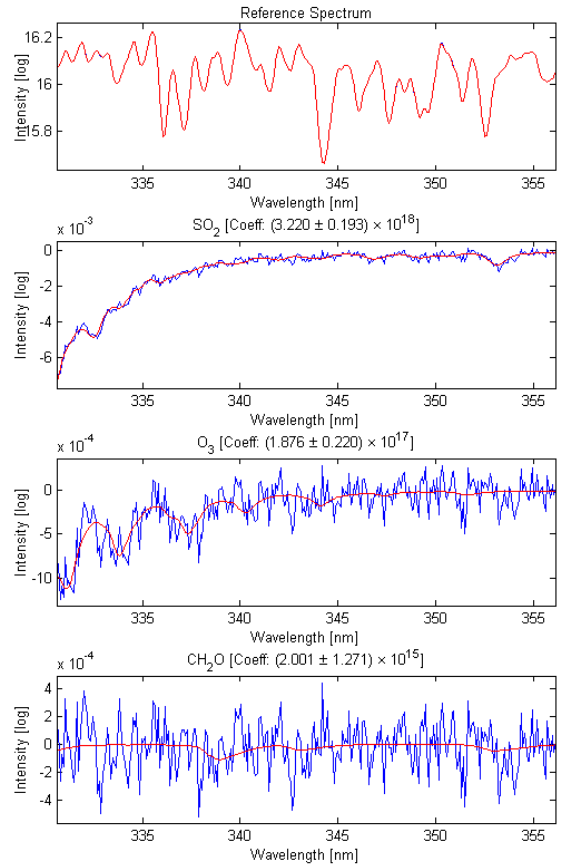

Figure 4. Exemplary fit result for the evaluation of $\mathrm{BrO}$ and $\mathrm{OClO}$ in the wavelength range between 330.6 and $356.3 \mathrm{~nm}$. This plume spectrum was recorded at the Etna observatory on 11 September 2012, 11:26 UTC; the corresponding FRS was recorded directly after the plume scan at 11:36 UTC. The BrO and OClO-SCDs are $S_{\mathrm{BrO}}=2.84 \times 10^{14}$ molecules cm $\mathrm{cm}^{-2}$ and $S_{\mathrm{OClO}}=7.51 \times 10^{13} \mathrm{molecules}^{-2}$ respectively. In addition, the fit results of the two ring spectra $(R, R 4)$ and the additionally included absorbers $\left(\mathrm{SO}_{2}, \mathrm{O}_{3}, \mathrm{O}_{4}, \mathrm{NO}_{2}, \mathrm{CH}_{2} \mathrm{O}\right)$ are shown as well as the corresponding residual (peak-to-peak value: $\bar{\Delta}_{\text {res }}=9.65 \times 10^{-4}$ ).

to account for inelastic scattering effects (Raman scattering) in the atmosphere (see e.g. Vountas et al., 1998). The first ring spectrum $(R)$ was calculated in the usual way from the respective FRS using the function of the evaluation software DOASIS (Kraus, 2006). The second ring spectrum $(R 4)$ was determined following the suggestions from Wagner et al. (2009) (for details see Appendix A1). Improvements due to the $R 4$ correction are discussed in Sect. A4, and a fit example with a strong $R 4$ signal is shown in Fig. A2. Literature cross sections of the individual absorbers $\left(\sigma_{i}\right.$, see Table 2) were convolved with the LSF of the respective spectrograph. During the convolution, the $\sigma_{i}$ were corrected for the solar $I_{0}$ effect and for spectral saturation (Platt and Stutz, 2008) using the corresponding functions in DOASIS. The latter was performed assuming typical SCDs for the respective species (e.g. $\mathrm{S}_{\mathrm{SO}_{2}}=2 \times 10^{18}$ molecules $\mathrm{cm}^{-2}$ ). In order to correct for any misalignment of the spectrograph, a slight shift $( \pm 0.1 \mathrm{~nm})$ and squeeze $( \pm 5 \%)$ was allowed for all fitted species (i.e. FRS, $R, R 4, \sigma_{i}$ ). Shift and squeeze of all $\sigma_{i}$ were linked to the strongest absorber and the two ring spectra were linked to the corresponding FRS in order to minimise the degrees of freedom during the fit-process. A third-order polynomial was included in the fitting routine to remove broad band extinction. An additional zero-order polynomial residing in intensity space was included (also referred to as offset polynomial) to account for intensity offsets in the spectra (e.g. due to stray light, for details see Kraus, 2006; Platt and Stutz, 2008). The measurement uncertainty $\left(\delta_{\text {meas }}\right)$ was estimated conservatively by multiplying the retrieved fit errors $\left(\delta_{\text {fit }}\right)$ with a factor of $U=4$ to account for potential abundances of fit residuals structures (Stutz and Platt, 1996, see e.g. Fig. A2). In the case of good fit results (which were assessed by the peak-to-peak values of the fit residuals $\bar{\Delta}_{\text {res }}$ ) the correction factor was reduced down to $U=3$ (i.e. for $\bar{\Delta}_{\text {res }} \leq 1.2 \times 10^{-3}$, see e.g. Fig. 4 ). Details regarding the error treatment are discussed in Sect. A2. The detection limits of the SCDs were defined to be twice the measurement uncertainty $\left(2 \times \delta_{\text {meas }}\right)$, thus representing a detection certainty of $95 \%$.

\subsection{Evaluation routines}

The focus of this study was regarding the data collected with the UV spectrograph (i.e. the DOAS evaluation of OClO, $\left.\mathrm{BrO}, \mathrm{SO}_{2}, \mathrm{IO}\right)$. In order to find the optimum evaluation range for each species, detailed sensitivity studies were performed including DOAS fit contour plots ("retrieval wavelength mapping", for details see Vogel et al., 2013). For the VIS data (i.e. the OBrO and OIO evaluation) these sensitivity studies were not performed since these data were of secondary interest. Therefore, we used a fixed correction factor of $U=5$ for the estimation of the corresponding measurement uncertainties of $\mathrm{OBrO}$ and $\mathrm{OIO}$ (for details see 
Table 1. Evaluation routines of the different species and the corresponding wavelength ranges $(\Delta \lambda)$. Furthermore included are additional absorbers and the correction factors $(U)$ used to estimate the measurement uncertainty from the DOAS fit error. In the case of $\mathrm{O}_{4}$, two different literature cross sections were used (labelled with (1) and (2), see also Table 2). The acronyms "uwr" and "lwr" indicate "upper" and "lower" evaluation wavelength ranges. Note: the two included ring spectra $(R, R 4)$ and the FRS are not included here (for details see Sect. 3.4).

\begin{tabular}{llll}
\hline Species & $\Delta \lambda[\mathrm{nm}]$ & Additional absorbers & $U$ \\
\hline $\mathrm{SO}_{2, \mathrm{wr}}$ & $314.8-326.8$ & $\mathrm{O}_{3}$ & $3-4$ \\
$\mathrm{SO}_{2, \text { uwr }}$ & $349.8-372.8$ & $\mathrm{BrO}, \mathrm{OClO}, \mathrm{O}_{3}, \mathrm{O}_{4}$, & $3-4$ \\
& & $\mathrm{NO}_{2}, \mathrm{CH}_{2} \mathrm{O}$ & \\
$\mathrm{BrO}$ & $330.6-356.3$ & $\mathrm{SO}_{2}, \mathrm{O}_{3},{ }^{(1)} \mathrm{O}_{4}, \mathrm{NO}_{2}, \mathrm{CH}_{2} \mathrm{O}$ & $3-4$ \\
and OClO & & & \\
OClO & & \\
$\mathrm{IO}$ & $363.6-391.3$ & $\mathrm{SO}_{2}, \mathrm{O}_{3},{ }^{(1)} \mathrm{O}_{4}, \mathrm{NO}_{2}$ & $3-4$ \\
OBrO & $416.6-441.3$ & $\mathrm{H}_{2} \mathrm{O}, \mathrm{NO}_{2},{ }^{(2)} \mathrm{O}_{4}$ & $3-4$ \\
OIO & $493.2-537.3$ & $\mathrm{H}_{2} \mathrm{O}, \mathrm{NO}_{2}, \mathrm{O}_{3}, \stackrel{(2)}{\mathrm{O}_{4}}$ & 5 \\
\hline
\end{tabular}

Sect. A2). All evaluation routines used in this study are summarised in Table 1, including the corresponding wavelength ranges, additional absorbers and the used correction factors $U$ for the DOAS fit errors. An overview of all corresponding literature cross sections $\left(\sigma_{i}\right)$ used is given in Table 2. Note that in the case of $\mathrm{O}_{4}$, two different literature cross sections were used because we found that different cross sections for the UV and VIS spectral ranges give the best results.

\subsubsection{BrO and OClO evaluation}

$\mathrm{BrO}$ and $\mathrm{OClO}$ were evaluated in the same wavelength range of $\Delta \lambda_{\mathrm{BrO}}, \mathrm{OClO}=330.6-356.3 \mathrm{~nm}$. An exemplary fit result for this wavelength range is shown in Fig. 4, including the two ring spectra $(R, R 4)$ and all additionally included absorbers as well as the corresponding fit residual. This example shows a rather unstructured residual with a peak-to-peak value of $\bar{\Delta}_{\text {res }}=9.65 \times 10^{-4}(1200$ co-added scans per spectrum); thus in this case a fit correction factor of $U=3$ was used.

Formaldehyde $\left(\mathrm{CH}_{2} \mathrm{O}\right)$ was included in the fitting routine in order to account for potential background abundances. In addition, $\mathrm{CH}_{2} \mathrm{O}$ could also be formed in the volcanic plume itself, for instance via $\mathrm{CH}_{4}$ oxidation (in the plume most likely initiated by the reaction with $\mathrm{Cl}$ atoms) or in the presence of nitrogen oxides (Platt and Stutz, 2008).

$\mathrm{OClO}$ was evaluated in a second "upper wavelength range" $\left(\Delta \lambda_{\mathrm{OClO}}\right.$,uwr $\left.=363.6-391.3 \mathrm{~nm}\right)$ in order to verify the retrieved SCDs in the standard range with respect to possible influences due to radiative transfer phenomena and/or crosscorrelations between different absorbers (for details see Appendix A3). However, this "upper" range was found to be influenced by larger fit uncertainties and was therefore not used
Table 2. Literature cross sections which were used in this study. Note that two different cross sections were used for $\mathrm{O}_{4}$.

\begin{tabular}{ll}
\hline Trace gas & Literature cross section \\
\hline $\mathrm{SO}_{2}$ & Hermans et al. (2009) $(298 \mathrm{~K})$ \\
$\mathrm{BrO}$ & Wilmouth et al. (1999) $(298 \mathrm{~K})$ \\
$\mathrm{OBrO}$ & Fleischmann et al. (2005) $(298 \mathrm{~K})$ \\
$\mathrm{OClO}$ & Bogumil et al. (2003) $(293 \mathrm{~K})$ \\
$\mathrm{O}_{3}$ & Burrows et al. (1999) $(221 \mathrm{~K})$ \\
${ }^{(1)} \mathrm{O}_{4}$ & Hermans et al. (2003) \\
${ }^{(2)} \mathrm{O}_{4}$ & Greenblatt et al. (1990) \\
& (vacuum, modified by J. Burkholder) \\
$\mathrm{IO}_{\mathrm{OIO}}$ & Spietz et al. (2005) $(298 \mathrm{~K})$ \\
$\mathrm{NO}_{2}$ & Spietz et al. (2005) $(298 \mathrm{~K})$ \\
$\mathrm{H}_{2} \mathrm{O}$ & Voigt et al. (2002) $(293 \mathrm{~K})$ \\
& Hitran database 2009 \\
$\mathrm{CH}_{2} \mathrm{O}$ & Meller and Moortgat $(2000)(298 \mathrm{~K})$ \\
\hline
\end{tabular}

for the discussion of our results. Nonetheless, both OClO retrievals show a good correlation (see Fig. A1).

\subsection{2 $\mathrm{SO}_{2}$ evaluation}

$\mathrm{SO}_{2}$ was evaluated in two different wavelength ranges. The "lower wavelength range" (lwr) between $\Delta \lambda_{\mathrm{SO}_{2}, \mathrm{lwr}}=314.8$ and $326.8 \mathrm{~nm}$ (e.g. Vogel, 2011) was used for $\mathrm{SO}_{2} \mathrm{SCDs}$ below $3 \times 10^{18} \mathrm{~cm}^{-2}$. In this wavelength region, especially below $320 \mathrm{~nm}, \mathrm{SO}_{2}$ shows strong absorption features. In order to avoid the well-known evaluation problems related to strong $\mathrm{SO}_{2}$ absorption in this "lower" wavelength range (see e.g. Kern et al., 2010; Bobrowski et al., 2010), $\mathrm{SO}_{2}$ was evaluated in a second, "upper" wavelength range of $\Delta \lambda \mathrm{SO}_{2}$,uwr $=$ $349.8-372.8 \mathrm{~nm}$ for $\mathrm{SO}_{2}$ SCDs exceeding $3 \times 10^{18} \mathrm{~cm}^{-2}$ (Hörmann et al., 2013). These problems - originating in the non-linear nature of the Beer-Lambert law - lead to an underestimation of the $\mathrm{SO}_{2} \mathrm{SCDs}$ in the "lower" wavelength range. This is clearly visible in the scatter plot of the $\mathrm{SO}_{2}$ retrieval in both evaluation ranges shown in Fig. A3 (i.e. flattening of the trend at large $\mathrm{SO}_{2} \mathrm{SCDs}$ ). Furthermore, an exemplary fit result of the upper wavelength range is shown in Fig. A2).

\subsubsection{IO, OIO and OBrO evaluation}

In addition to the evaluation of $\mathrm{BrO}, \mathrm{OClO}$ and $\mathrm{SO}_{2}$, abundances of $\mathrm{IO}, \mathrm{OBrO}$ and $\mathrm{OIO}$ were investigated. The details of the corresponding evaluation routines for these species can be found in Table 1 .

\subsection{Estimation of $\mathrm{OClO}$ and $\mathrm{BrO}$ concentrations from plume cross-section scans}

The data from plume cross-section scans were used to estimate mean concentrations $\left(\bar{c}_{i}\right)$ of $\mathrm{BrO}$ and $\mathrm{OClO}$ in the 
plume. This was done assuming a circular plume cross section and straight line absorption light paths through the plume. Any potential deviations due to radiative transfer effects (RTE, e.g. multiple scattering, light dilution; for details see e.g. Kern et al., 2010; Mori et al., 2006) or deviations from the assumed circular shape were not considered in this estimation. The plume diameter $\left(\varnothing_{\mathrm{pl}}\right)$ was estimated from the angular extend of the $\mathrm{SO}_{2} \mathrm{SCD}$ profile and the distance to the plume (see also e.g. Bobrowski et al., 2003; Lee et al., 2005). The corresponding $\mathrm{SO}_{2} \mathrm{SCDs}$ were used as a proxy for the lengths of the absorption light paths $\left(l_{\mathrm{eff}, i}\right)$ in the plume, whereas the largest $\mathrm{SO}_{2} \mathrm{SCD}$ of the scan was assigned to $\emptyset_{\mathrm{pl}}$. Based on that, the $l_{\mathrm{eff}, i}$ could be estimated for all scan spectra $i: l_{\mathrm{eff}, i}=\emptyset_{\mathrm{pl}} / S_{\mathrm{SO}_{2}, \max } \times S_{\mathrm{SO}_{2}, i}$. Using this, the mean concentrations $\left(\bar{c}_{j, i}\right)$ of the measured species $j$ (e.g. OClO, BrO) were estimated: $\bar{c}_{j i}=S_{j, i} / l_{\text {eff }, i}$. The corresponding uncertainties were determined from the DOAS-fit errors and the uncertainties in the estimation of the plume diameter using Gaussian error propagation.

\subsection{Determination of $\mathrm{ClO}$ concentrations}

Following Kern et al. (2009), we estimated ClO concentrations from the retrieved $\mathrm{BrO}$ and OClO-SCDs assuming steady state between the formation of OClO (Reaction R7) and its photolytic destruction (Reaction R8):

$\mathrm{ClO}=\frac{J_{\mathrm{OClO}}}{k_{7}} \times \frac{[\mathrm{OClO}]}{[\mathrm{BrO}]} \approx \frac{J_{\mathrm{OClO}}}{k_{7}} \times \frac{S_{\mathrm{OClO}}}{S_{\mathrm{BrO}}}$.

Since $\mathrm{BrO}$ and $\mathrm{OClO}$ were evaluated in the same wavelength range, differences in the retrieved SCDs $\left(S_{i}\right)$ due to differences in the radiative transfer can be neglected. We therefore assume that the ratio of the $\mathrm{OClO}$ and $\mathrm{BrO}$ concentrations is approximately the same as the ratio of the respective SCDs (Eq. 1). The OClO photolysis frequencies $J_{\mathrm{OClO}}$ used for the calculation of the $\mathrm{ClO}$ concentrations were simulated for our data set by E. Jäkel (Leipzig Institute for Meteorology). For the simulation, the 1-D radiative transfer model libRadtran (Mayer and Kylling, 2005) was used. The photolysis frequencies were determined for a set of chosen spectra from the field campaign and were between $5.1 \times 10^{-2} \mathrm{~s}^{-1}\left(\mathrm{SZA} \approx 62^{\circ}\right)$ and $7.1 \times 10^{-2} \mathrm{~s}^{-1}\left(\mathrm{SZA} \approx 34^{\circ}\right)$, slightly slower than typical values found in the stratosphere (e.g. $J_{\mathrm{str}, \mathrm{OClO}} \approx 7.6 \times 10^{-2} \mathrm{~s}^{-1}$; Birks et al., 1977). Uncertainties in the determination of the ClO-concentrations were estimated using Gaussian error propagation.

\subsection{Determination of the plume age $(\tau)$ and meteorological data}

The plume age $(\tau)$ was estimated using meteorological information (i.e. wind speed and direction) and the measurement geometry (i.e. geo-locations of instrument and craters, telescopes viewing direction). A typical measurement geometry at Mt. Etna is sketched in Fig. 5. The intersection of the

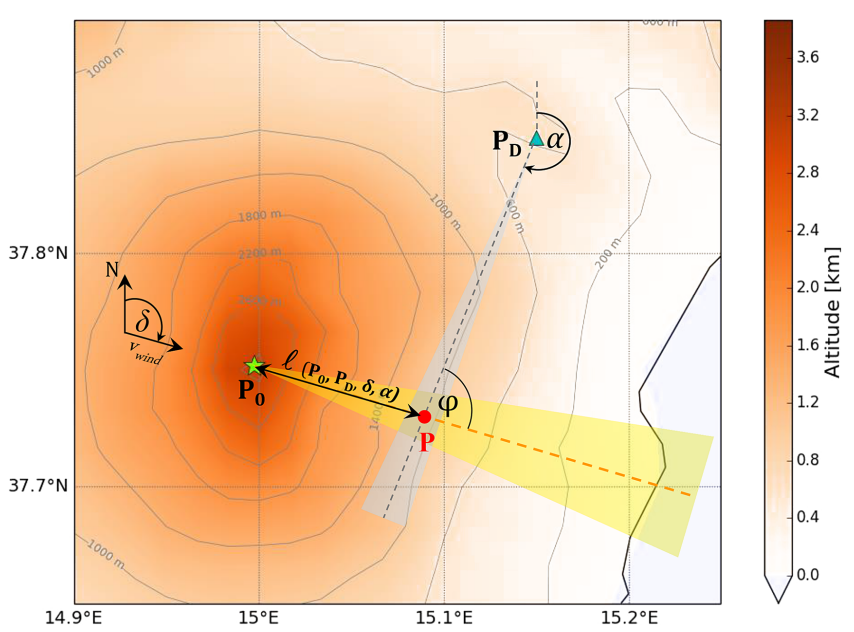

Figure 5. Typical scan geometry at Mt. Etna: the emission source is located at $\boldsymbol{P}_{0}$, and the DOAS instrument is located at $\boldsymbol{P}_{\mathrm{D}}$. The intersection point of plume and telescope $\boldsymbol{P}$ is determined from the viewing direction of the telescope ( $\alpha$, gray dotted line) and the plume direction ( $\delta$, orange dotted line). Typical uncertainties of $\alpha$ and $\delta$ are indicated by the gray and yellow shaded area respectively. The plume age $\tau$ is determined by dividing $l\left(P_{0}, P_{\mathrm{D}}, \delta, \alpha\right)$ by the wind velocity $v_{\text {wind }}$.

telescopes viewing direction with the plume determines the distance $l$. Based on that, the plume age was estimated as follows:

$\tau=\frac{l}{v_{\text {wind }}}$.

The azimuthal alignment of the instrument was performed using a compass. Due to possible disturbances of the planetary magnetic field by the volcano, we estimated the instruments azimuth-uncertainty to $\pm 3^{\circ}$ (gray shaded area in Fig. 5). Wind directions were estimated using own observations/notes and - on clear days - satellite pictures from the MODIS network (Aqua, Terra satellites). Wind velocities were partly retrieved from simultaneously performed $\mathrm{SO}_{2}-$ camera measurements and from own observations. From the 16. September we additionally monitored meteorological data using a meteorological station, which was installed on the southern side of the craters. Uncertainties in the plume age estimation were determined using Gaussian error propagation, a detailed discussion of these, especially relative and absolute errors can be found in Appendix A5.

\subsection{Correction for stratospheric BrO}

Typical vertical column densities (VCDs) of stratospheric $\mathrm{BrO}$ are of the order of several $10^{13}$ molecules $\mathrm{cm}^{-2}$ (e.g. Schofield et al., 2004; Sinnhuber et al., 2005). Therefore, MAX-DOAS measurements of volcanic BrO (using scattered sunlight) can be significantly disturbed by stratospheric $\mathrm{BrO}$ signals under certain conditions. Based on the geo- 
metrical air-mass factor (AMF: $\mathrm{X}=1 / \cos (\Theta))$ and by assuming a constant stratospheric BrO-VCD of $V_{\text {str, } \mathrm{BrO}}=$ $4.0 \times 10^{13}$ molecules $\mathrm{cm}^{-2}$ (Sinnhuber et al., 2005; Schofield et al., 2004) a correction was implemented to account for additional stratospheric BrO signals in our retrieved SCDs. A detailed discussion including simplifications and sensitivity studies can be found in Appendix A6.

For our data set, we found that deviations in the volcanic $\mathrm{BrO}$ column due to superimposed stratospheric $\mathrm{BrO}$ signals are smaller than $5 \%$ in $85 \%$ of the analysed spectra. Only $8 \%$ of the retrieved BrO SCDs showed deviations exceeding the corresponding fit uncertainty. All of these spectra were either recorded before $08: 15$ or after $16: 45 \mathrm{LT}\left(64.6^{\circ}<\mathrm{SZA}<\right.$ $83.2^{\circ}$ ), which shows the importance of this correction especially for measurements performed in the early morning and late afternoon.

\subsection{0 $\mathrm{SO}_{2}$ as volcanic plume proxy - analysis of $\mathrm{X}_{m} \mathrm{O}_{n} / \mathrm{SO}_{2}$ ratios}

In order to study spatial (and temporal) variations of the retrieved halogen species $\mathrm{X}_{m} \mathrm{O}_{n}$, molar $\mathrm{SO}_{2}$ ratios of these species were analysed (i.e. $\mathrm{X}_{m} \mathrm{O}_{n} / \mathrm{SO}_{2}$ ratios), whereas $\mathrm{SO}_{2}$ was treated as volcanic plume proxy due to its comparatively long tropospheric lifetime (e.g. McGonigle et al., 2004; Lee et al., 2011; Beirle et al., 2014). This is a common method to avoid signal variations due to atmospheric dilution effects (e.g. Bobrowski et al., 2003; Bobrowski and Platt, 2007; Bobrowski et al., 2007; Kern et al., 2009). Furthermore, compared to the individual SCDs the $\mathrm{X}_{m} \mathrm{O}_{n} / \mathrm{SO}_{2}$ ratios are much less affected by RTE such as light dilution or multiple scattering (Lübcke et al., 2014). We therefore neglect any potential influences of these effects on our retrieved trace gas ratios. The discussion of our results mostly relates to the measurements performed at the Etna observatory. Especially for these data, potential influences due to RTE on the retrieved ratios should be negligible because of the proximity to the plume, the relatively high altitude (i.e. low plume dilution; see e.g. Mori et al., 2006; Kern et al., 2010) and the fairly good visibility during most of the measurements (i.e. low aerosol scattering; for details see Sect. 3.2). The errors and detection limits of the $\mathrm{X}_{m} \mathrm{O}_{n} / \mathrm{SO}_{2}$ ratios were calculated from the SCD errors using Gaussian error propagation.

\section{Results and discussion}

Most of the significant $\mathrm{OClO}$ detections (i.e. 99.2\%) are related to the measurements performed at the Etna observatory (11-13 September 2012), where the largest SCDs can be found due to the proximity to the craters (little plume dispersion). Out of 677 significant $\mathrm{SO}_{2}$ detections during the whole campaign, $\mathrm{OClO}$ could be detected in 119 spectra up to plume ages of $6 \mathrm{~min}$. $\mathrm{BrO}$ was detected in 452 spectra (269 of those recorded at the observatory) at plume ages up to
23 min. As expected, $\mathrm{OClO}$ was less abundant compared to $\mathrm{BrO}$ with a mean $\mathrm{OClO} / \mathrm{BrO}$ ratio of 0.16 . The retrieved SCDs of $\mathrm{OClO}, \mathrm{BrO}$ and $\mathrm{SO}_{2}$ ranged between 0.4 and $2.0 \times$ $10^{14}$ molecules $\mathrm{cm}^{-2}, 0.3$ and $11.4 \times 10^{14}$ molecules $\mathrm{cm}^{-2}$ and 0.03 and $8.77 \times 10^{18}$ molecules $\mathrm{cm}^{-2}$ respectively. Furthermore, potential abundances of $\mathrm{IO}, \mathrm{OIO}$ and $\mathrm{OBrO}$ were investigated but none of these species could be detected significantly. Upper limits of IO, OIO and $\mathrm{OBrO}$ were determined and are presented in Sect. 4.2.

\subsection{OClO and BrO results}

In Fig. 6 we plotted all retrieved $\mathrm{OClO}$ and $\mathrm{BrO}$ SCDs as a function of the corresponding $\mathrm{SO}_{2} \mathrm{SCDs}(\mathrm{A}, \mathrm{B})$ and furthermore $\mathrm{OClO}$ vs. $\mathrm{BrO}(\mathrm{C})$. Both $\mathrm{BrO}$ and $\mathrm{OClO}$ show a good correlation to $\mathrm{SO}_{2}$ (Fig. 6a, b), indicating that these species could only be detected in volcanic plume spectra. Average ratios of $1.65 \times 10^{-4}$ for $\mathrm{BrO} / \mathrm{SO}_{2}$ (Fig. 6a) and $3.17 \times 10^{-5}$ for $\mathrm{OClO} / \mathrm{SO}_{2}$ (Fig. 6b) were found (linear regression). These values are in good agreement with previous findings (e.g. Bobrowski et al., 2007; Bobrowski and Giuffrida, 2012; General et al., 2015). For the linear regression, only significant detections at plume ages exceeding $3 \mathrm{~min}$ were considered (blue dots in Fig. 6). Measurements at plume ages smaller than 3 min (green dots) were excluded because in this plume age range the formation of $\mathrm{BrO}$ and $\mathrm{OClO}$ is not yet fully developed and therefore the $\mathrm{X}_{m} \mathrm{O}_{n} / \mathrm{SO}_{2}$ ratios are smaller (for details see Sect. 4.1.3). The corresponding average $\mathrm{OClO} / \mathrm{BrO}$ ratio (at plume ages exceeding $3 \mathrm{~min}$ ) is $0.16 \pm 0.08$ and shows a very good correlation between both species in this plume age range $\left(R^{2}=0.9447\right)$. Young plume measurements (green dots, $\tau<$ $3 \mathrm{~min}$ ), however, rather indicate stronger fluctuations of the $\mathrm{OClO} / \mathrm{BrO}$ ratio $\left(R^{2}=0.4717\right)$.

\subsubsection{Results from individual scans}

In order to study the chemical evolution of $\mathrm{BrO}$ and $\mathrm{OClO}$, we analysed the corresponding ratios with $\mathrm{SO}_{2}\left(\mathrm{BrO} / \mathrm{SO}_{2}\right.$, $\mathrm{OClO} / \mathrm{SO}_{2}$ ratio). In Fig. 7 examples of plume evolution scans of both ratios are plotted for different plume age ranges (i.e. Fig. 7a-e). Furthermore, an exemplary plume crosssection scan is shown in Fig. 7f. As discussed in Sect. 3.8 and Appendix A5, plume age errors were separated into a geometrical contribution ( $x$ error bars) and a percentage contribution due to uncertainties in the wind velocity $(\Delta \tau$, plot header). We explicitly point out again that these are not to be treated as independent random plume age errors between each of the scan spectra but are strongly correlated and, thus, indicate a stretch/squeeze of the whole data set towards smaller or larger plume ages. The plume evolution scans of the $\mathrm{BrO} / \mathrm{SO}_{2}$ ratio (Fig. $7 \mathrm{a}-\mathrm{c}$ ) show a strong increase in the young plume (Fig. 7a), stabilising after approximately $150 \mathrm{~s}$ downwind. This trend could be observed in six individual measurements performed in the young plume 

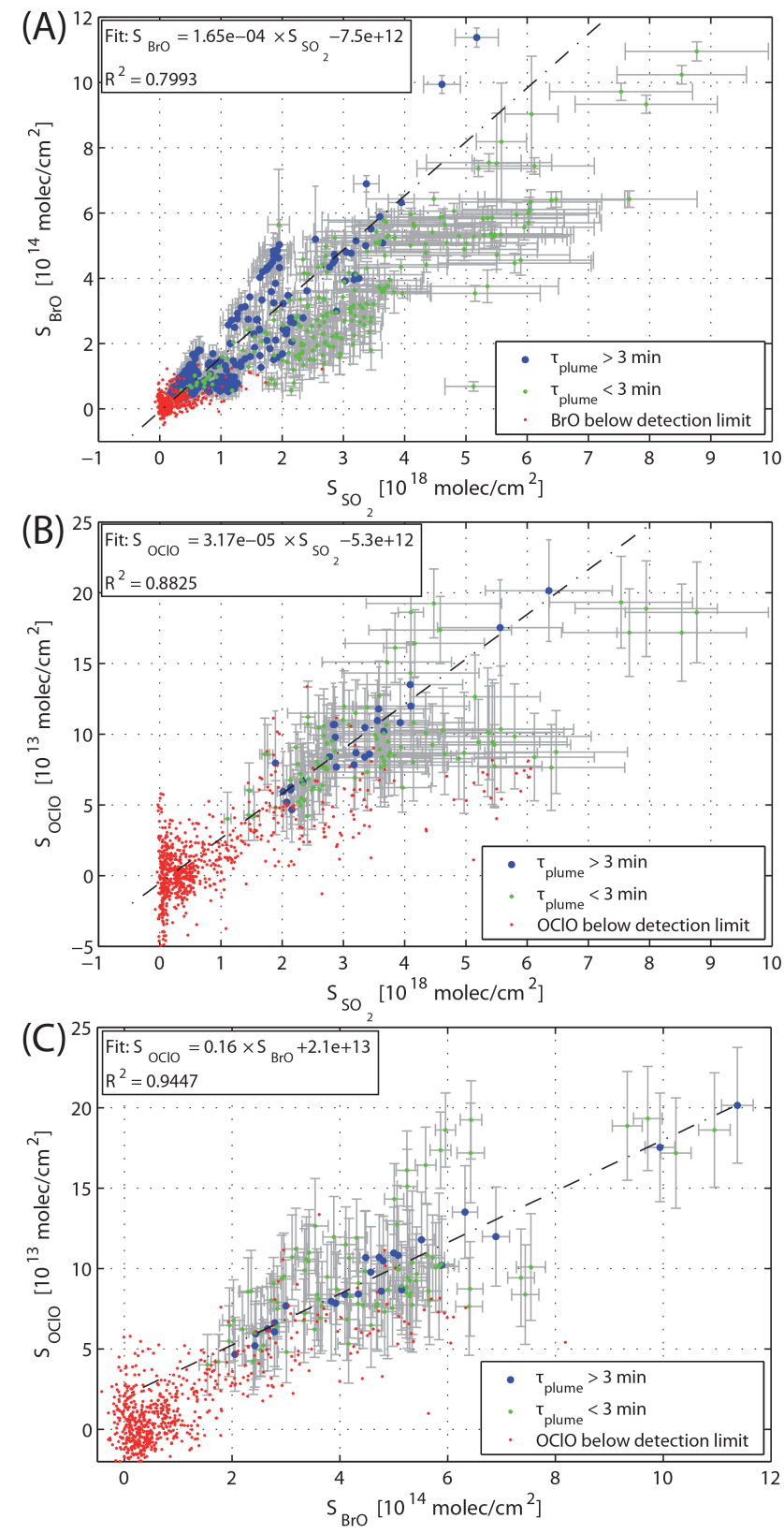

Figure 6. Retrieved slant column densities (SCDs) of $\mathrm{BrO}$ (a) and $\mathrm{OClO}$ (b) as a function of the retrieved $\mathrm{SO}_{2} \mathrm{SCDs}$ and (c), $\mathrm{OClO}$ vs. BrO SCDs. The measurements were subdivided by their plume age $\tau$ (i.e. $\tau<3 \mathrm{~min}$ : green stars, $\tau>3 \mathrm{~min}$ : blue dots) due to smaller $\mathrm{BrO} / \mathrm{SO}_{2}$ and $\mathrm{OClO} / \mathrm{SO}_{2}$ ratios in the young plume (see also Sect. 4.1.3). Measurements below the detection limit of $\mathrm{BrO}$ (a) and $\mathrm{OClO}(\mathbf{b})$ are indicated by red dots. We determined mean ratios in the $\tau>3$ min range (blue dots) by applying a linear fit and found values of $\mathrm{BrO} / \mathrm{SO}_{2}=1.65 \times 10^{-4}$ and $\mathrm{OClO} / \mathrm{SO}_{2}=3.17 \times 10^{-5}$ respectively. The $\mathrm{OClO} / \mathrm{BrO}$ ratio (c) was found to be 0.16 for $\tau>3 \mathrm{~min}$ and approximately 0.22 in the young plume. (i.e. $\tau<5 \mathrm{~min}$ ); details are discussed in Sect. 4.1.3. At larger plume ages, the $\mathrm{BrO} / \mathrm{SO}_{2}$ ratios show a rather constant behaviour with only slight variations. The discussion of potential trends of the corresponding $\mathrm{OClO} / \mathrm{SO}_{2}$ ratio in the young plume (at $\tau \lesssim 2 \mathrm{~min}$ ) is more difficult for the results retrieved from the individual scans (see e.g. Fig. 7d-e), since the retrieved values are often below our (conservative) choice for the detection limit. Therefore, we refer to Sect. 4.1 .3 where we statistically analyse and confirm these apparent trends of increasing $\mathrm{BrO} / \mathrm{SO}_{2}$ and $\mathrm{OClO} / \mathrm{SO}_{2}$ ratios in the young plume. For plume ages exceeding $2 \mathrm{~min}$, we found rather low variations in the retrieved $\mathrm{OClO} / \mathrm{SO}_{2}$ ratios (similar to our $\mathrm{BrO}$ observations for this plume age range, cf. Fig. 7e, b). Due to the higher $S / N$ ratio, $\mathrm{BrO}$ could also be analysed at larger plume ages (i.e. $\tau>5 \mathrm{~min}$ ). An exemplary $\mathrm{BrO}$ scan in the aged plume is shown in Fig. 7c. It covers a plume age range between 8 and $22 \mathrm{~min}$ and shows rather stable $\mathrm{BrO} / \mathrm{SO}_{2}$ ratios around $1.7 \times 10^{-4}$. A slight but not significant decrease of approximately $17 \%$ might be observable between 8 and 10 min downwind.

The retrieved $\mathrm{BrO} / \mathrm{SO}_{2}$ ratios in Fig. $7 \mathrm{a}-\mathrm{c}$ range from $8 \times 10^{-5}$ to $1.8 \times 10^{-4}$ in the $\tau>3$ min regime (i.e. after reaching steady state). These variations could, for example, be caused by superimposed diurnal profiles (note: the scans were performed on different days and at different times) or varying volcanic activity.

\subsubsection{Cross-sectional distribution of $\mathrm{BrO}$ and $\mathrm{OClO}$}

Previous studies showed increased $\mathrm{BrO} / \mathrm{SO}_{2}$ ratios at the edges of the plume (e.g. Bobrowski et al., 2007; Louban et al., 2009; General et al., 2015). These are likely due to a limited transport of tropospheric $\mathrm{O}_{3}$ and $\mathrm{HO}_{2}$ radicals towards the plume centre (see also Sect. 2). Since OClO is most likely formed in the "BrO+ClO" reaction, it is likely that also the $\mathrm{OClO} / \mathrm{SO}_{2}$ ratios show enhanced values at the edges of the plume. In order to elaborate this issue of increased $\mathrm{X}_{m} \mathrm{O}_{n} / \mathrm{SO}_{2}$ ratios at the edges of the plume, crosssection scans perpendicular to the plume propagation axis (see Fig. 3b) were performed. One exemplary plume crosssection scan of the $\mathrm{BrO} / \mathrm{SO}_{2}$ ratio is shown in Fig. 7f. Please note the comparatively long time necessary to perform a full plume scan (here $\sim 40 \mathrm{~min}$ ), which is due to the large number of co-added spectra in each measurement point. In order to investigate the issue of potentially increased ratios at the edges, we analysed the retrieved ratios of a given crosssection scan as a function of the corresponding $\mathrm{SO}_{2} \mathrm{SCDs}$ (which indicate whether a spectrum was recorded in the centre or at the edge of the plume). In most of the scans, we found indications of increased ratios at the plume edges (i.e. at low $\mathrm{SO}_{2} \mathrm{SCDs}$ compared to the corresponding "plume centre" spectra). However, from our data set these observations could unfortunately not be confirmed with certainty due to comparatively large measurement uncertainties at the plume edges (i.e. at small SCDs). This can be seen in the ex- 


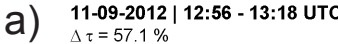

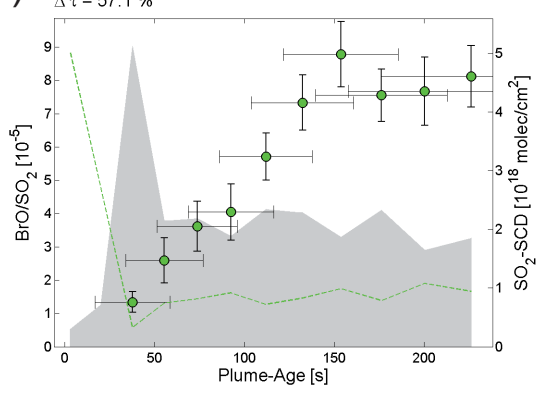

11-09-2012| 12:56 - 13:18 UTC

d) $\Delta \tau=57.1 \%$

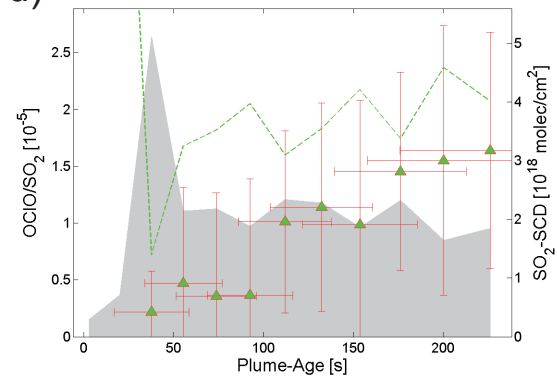

b)

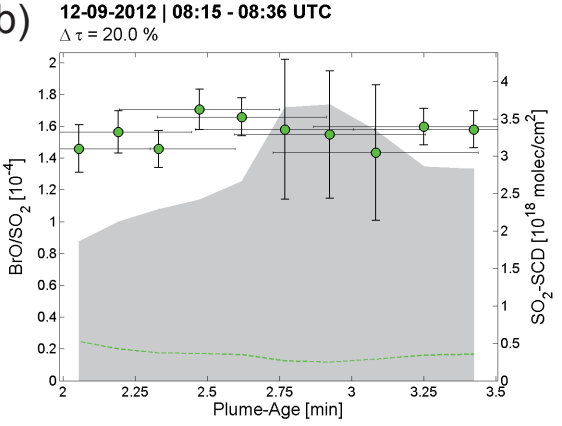

e) $12-09-2012 \mid 08: 15$ - 08:36 UTC

e)

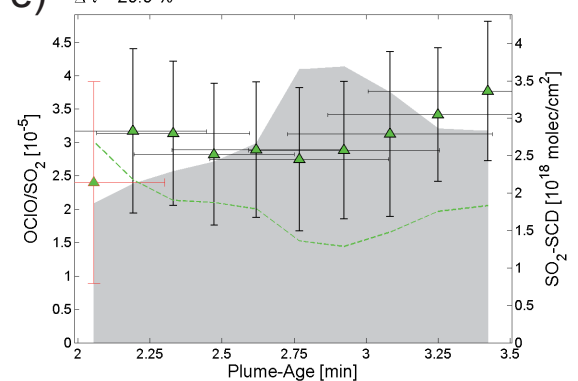

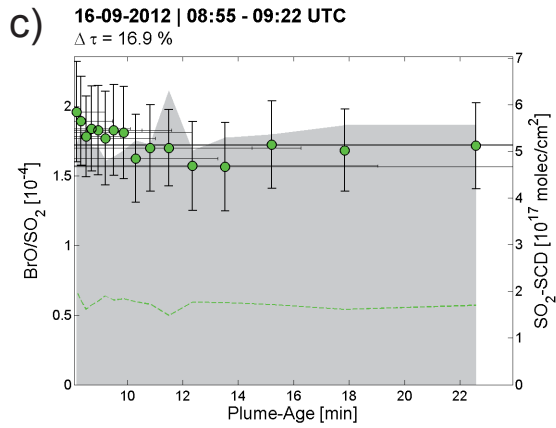

f) 16-09-2012| 08:02 - 08:38 UTC

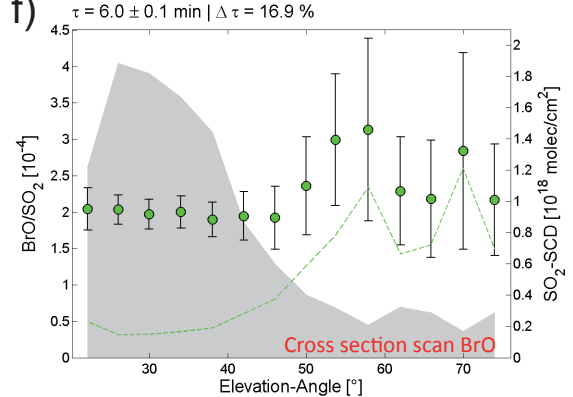

Figure 7. Plume evolution scans of the $\mathrm{BrO} / \mathrm{SO}_{2}$ ratio $(\mathbf{a}-\mathbf{c})$ and the $\mathrm{OClO} / \mathrm{SO}_{2}$ ratio (d-e) (note the different time scales). A sample plume cross-section scan of $\mathrm{BrO} / \mathrm{SO}_{2}$ is shown in (f). The $\mathrm{BrO} / \mathrm{SO}_{2}$ (green circles) and the $\mathrm{OClO} / \mathrm{SO}_{2}$ (green triangles) ratios are plotted with their corresponding detection limits (green dotted line). Red error bars indicate measurements below the detection limit. The $\mathrm{SO}_{2} \mathrm{SCDs}_{\mathrm{s}}$ are plotted as gray shaded areas (right axis). The $\mathrm{BrO} / \mathrm{SO}_{2}$ ratio increases in the young plume and levels off at larger plume ages $(\tau \lesssim 3$ min, a, b). The corresponding $\mathrm{OClO} / \mathrm{SO}_{2}$ ratios (d, e) show a similar trend but are technically below the detection limit in the young plume (d). In (c), a plume evolution scan of the $\mathrm{BrO} / \mathrm{SO}_{2}$ ratio in the aged plume (8-22 min downwind) is shown. A rather stable trend is observable with indications of a slight decrease between 8 and 10 min downwind. In (f), a cross-section scan of BrO is plotted, showing indications of enhanced $\mathrm{BrO} / \mathrm{SO}_{2}$ ratios at low $\mathrm{SO}_{2} \mathrm{SCDs}$ (i.e. at the edges of the plume).

emplary cross-section scan shown in Fig. 7f, which also visualises the problems related to the plume edge spectra: the $\mathrm{BrO} / \mathrm{SO}_{2}$ ratios show increased values at low $\mathrm{SO}_{2} \mathrm{SCDs}$, but considering the larger errors (due to low $\mathrm{BrO}$ and $\mathrm{SO}_{2}-\mathrm{SCDs}$ ) it is not possible to draw any conclusions with certainty. However, by ignoring the comparatively large errors in the edge measurements and only analysing the absolute values of the retrieved ratios, we could observe this trend of increased $\mathrm{BrO} / \mathrm{SO}_{2}$ ratios at the edges in $76 \%$ of all 25 suited crosssection scans. In the case of $\mathrm{OClO} / \mathrm{SO}_{2}$ it was even more difficult to draw confident conclusions due to the weaker $\mathrm{OClO}$ signal. Nonetheless, in five of - in total - nine suited crosssection scans, indications of enhanced $\mathrm{OClO} / \mathrm{SO}_{2}$ ratios at low $\mathrm{SO}_{2} \mathrm{SCDs}$ could be found.

\subsubsection{The BrO and OClO evolution in the plume}

\section{Statistical analysis of the young plume evolution}

All plume evolution scans performed in the young plume clearly showed increasing $\mathrm{BrO} / \mathrm{SO}_{2}$ ratios at plume ages $(\tau)$ smaller than $150 \mathrm{~s}$ (see e.g. Fig. 7a). In the case of OClO, we found strong indications of a similar trend in the young plume. However, from our individual scans this could not be validated with certainty due to comparatively large measurement uncertainties in the $\mathrm{OClO}$ retrieval (i.e. in most cases the $\mathrm{OClO} / \mathrm{SO}_{2}$ ratios appeared to be below the detection limit in this plume age range, see e.g. Fig. 7d). In order to further elaborate this issue and especially the young plume evolution of $\mathrm{OClO}$, we therefore performed a statistical analysis of the retrieved $\mathrm{X}_{m} \mathrm{O}_{n} / \mathrm{SO}_{2}$ ratios as a function of the plume age. The plume was subdivided into six plume age intervals between 0 and 250 s downwind (i.e. 42 sinterval $^{-1}$ ) and the retrieved $\mathrm{X}_{m} \mathrm{O}_{n} / \mathrm{SO}_{2}$ ratios were assigned to the corresponding plume age interval accordingly. Only spectra related to the plume centre were considered by including only measurements showing $\mathrm{SO}_{2} \mathrm{SCDs}$ larger than $1.5 \times 10^{18}$ molecules $\mathrm{cm}^{-2}$. This was done to avoid possible falsifications due to potentially enlarged ratios at the edges of the plume (for details see Sect. 4.1.2). Furthermore, we did not distinguish between measurements above or below the respective detection limits of $\mathrm{BrO}$ and $\mathrm{OClO}$. Based on this selection, we determined the mean value of the retrieved $\mathrm{X}_{m} \mathrm{O}_{n} / \mathrm{SO}_{2}$ ratios for each $\tau$ interval. The corresponding uncertainties ( $\Delta$, i.e. $y$ axis error bars in Fig. 8) for the averaged ratios were determined from the mean of the individual errors $\left(\overline{\sigma_{i}}\right)$ divided by the inverse square root of the number $N$ of averaged spectra in each interval: $\Delta=\overline{\sigma_{i}} / \sqrt{N}$. 

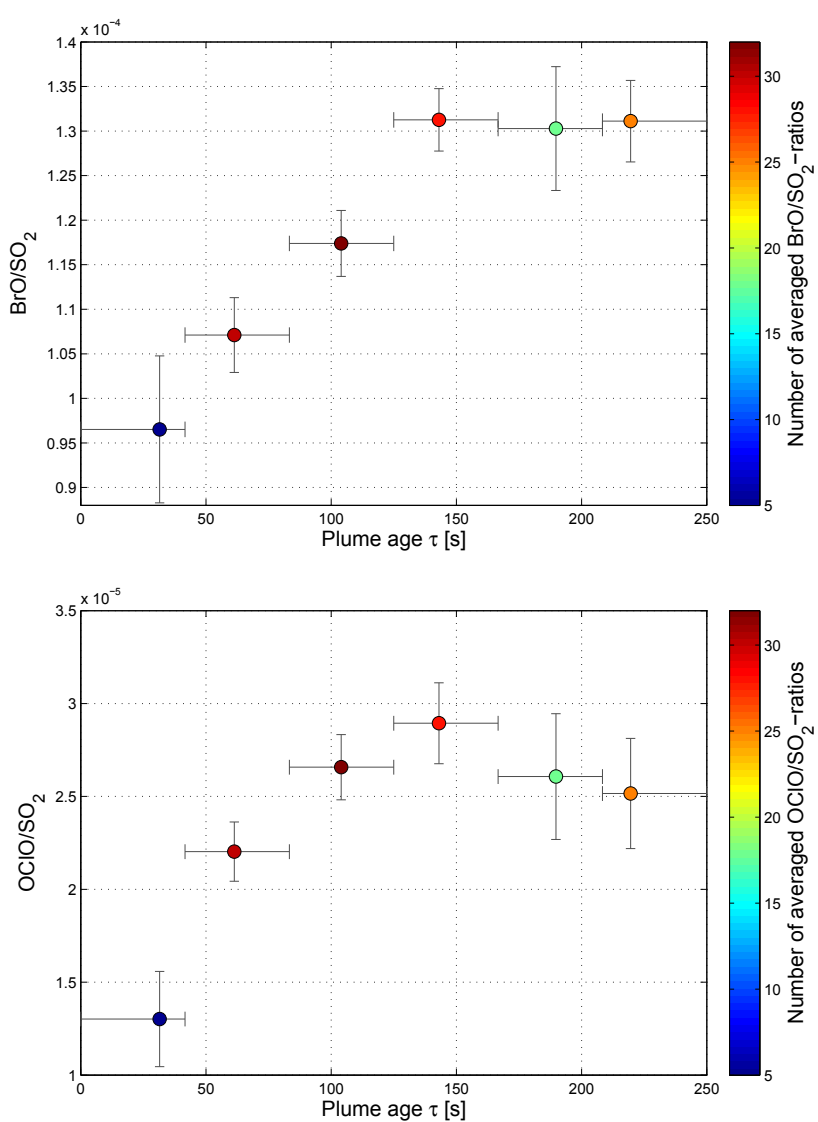

Figure 8. The young plume evolution of the $\mathrm{BrO} / \mathrm{SO}_{2}$ ratio (top) and the $\mathrm{OClO} / \mathrm{SO}_{2}$ ratio (bottom): the colour code indicates the number of averaged individual measurements. The errors of the ratios were determined from the uncertainties of the individual measurements using Gaussian error propagation (for details see text). The horizontal error bars denote the respective plume age interval, which was used for averaging. The position of the averaged ratios for each plume age interval represents the mean plume age of the individual spectra included in this range. For both species, we observed an increase in the young plume levelling off at $\tau=142 \mathrm{~s}$. For larger plume ages, the $\mathrm{BrO} / \mathrm{SO}_{2}$ ratio shows rather constant values (at $\sim 1.3 \times 10^{-4}$ ) whereas the $\mathrm{OClO} / \mathrm{SO}_{2}$ ratio slightly decreases, which is probably due to plume dilution.

The results of this statistical approach are plotted in Fig. 8 and clearly show an increase of the $\mathrm{OClO} / \mathrm{SO}_{2}$ ratio in the young plume. Furthermore, they confirm the increase of the $\mathrm{BrO} / \mathrm{SO}_{2}$ ratio which was already observed in the individual scans. Both $\mathrm{BrO} / \mathrm{SO}_{2}$ and $\mathrm{OClO} / \mathrm{SO}_{2}$ level off after approximately $142 \mathrm{~s}$. However, while $\mathrm{BrO} / \mathrm{SO}_{2}$ reaches a constant plateau of $\sim 1.3 \times 10^{-4}$ at larger plume ages, the $\mathrm{OClO} / \mathrm{SO}_{2}$ ratio rather seems to follow a slight - but statistically not significant - decreasing trend. Indications of such a decrease could also be observed in some of the individual scans and are likely due to plume dilution (decreasing $\mathrm{BrO}$ and $\mathrm{ClO}$ concentrations).
The retrieved $\mathrm{BrO} / \mathrm{SO}_{2}$ and $\mathrm{OClO} / \mathrm{SO}_{2}$ ratios in the aged plume (i.e. $\tau>142 \mathrm{~s}$, see Fig. 8) are slightly lower compared to the values retrieved in the corresponding scatter plots (Fig. 6) of the whole data set (i.e. $\overline{\mathrm{BrO} / \mathrm{SO}_{2}}=1.65 \times 10^{-4}$, $\overline{\mathrm{OClO} / \mathrm{SO}_{2}}=3.17 \times 10^{-5}$ ). One explanation for this deviation could be that spectra related to the plume edges (which showed indications of elevated $\mathrm{BrO} / \mathrm{SO}_{2}$ and $\mathrm{OClO} / \mathrm{SO}_{2}$ ratios; see Sect. 4.1.2) were excluded in the statistical approach. Further possible reasons could be that the long-term trend of both species (i.e. $\tau>250 \mathrm{~s}$ ) is still increasing (which should, however, be unlikely for OClO due to plume dilution) or that a superimposed diurnal signal might have influenced the statistics. Moreover, both long- and short-term variations of the volcanic activity might have affected the retrieved ratios. Nonetheless, the main objective of this study, namely the young plume increase of both species, could be validated. In order to further elaborate the long-term trend of $\mathrm{BrO}$ and $\mathrm{OClO}$ (and/or diurnal profiles, variations due to volcanic activity), more measurements are necessary especially in the ageing plume.

The similarities in the trends of $\mathrm{OClO}$ and $\mathrm{BrO}$ in the young plume (i.e. increase in the young plume and steady state after about 2-3 min) strongly support the assumption that $\mathrm{OClO}$ is mainly formed via the " $\mathrm{BrO}+\mathrm{ClO}$ " Reaction (R7).

\subsubsection{Photochemical formation of $\mathrm{BrO}$ and $\mathrm{OClO}$ at low solar radiances}

The "bromine explosion" includes the photolysis of the $\mathrm{Br}_{2}$ molecule (Reaction R5, for details see Sect. 1). Kern et al. (2009) investigated night-time abundances of $\mathrm{BrO}$ at Masaya volcano, Nicaragua; however, they were not able to detect significant $\mathrm{BrO}$ levels during night-time.

Although MAX-DOAS measurements can only be made when a sufficient amount of sunlight is available, we were able to observe the onset of the $\mathrm{BrO}$ and $\mathrm{OClO}$ formation. The corresponding point measurement (for details see Sect. 3.3) was performed in the early morning on 13 September 2012 between 05:20 and 06:20 UTC (SZA range: 83.2-70.1 ${ }^{\circ}$, sunrise: 04:40 UTC). The data are plotted in Fig. 9 and clearly shows an increase of the $\mathrm{BrO} / \mathrm{SO}_{2}$ ratio with time between 05:20 and 05:32 UTC (see Fig. 9, top) and a constant ratio afterwards. A similar trend can be observed for the corresponding $\mathrm{OClO} / \mathrm{SO}_{2}$ ratios (see Fig. 9, bottom) which were averaged (nearest-neighbour averaging) due to larger measurement uncertainties. Compared to $\mathrm{BrO} / \mathrm{SO}_{2}$, the increase of $\mathrm{OClO} / \mathrm{SO}_{2}$ appears to be delayed by approximately $30-40 \mathrm{~min}$ reaching a plateau around 06:15 UTC. One possible explanation for such a delayed increase could be that the availability of $\mathrm{Cl}$ atoms is delayed with respect to $\mathrm{Br}$ during this time of the day. The corresponding $\mathrm{SO}_{2}$ profile is fairly constant showing typical plume centre values around $5 \times 10^{18}$ molecules $\mathrm{cm}^{-2}$. This suggests that the measurement conditions (e.g. wind 


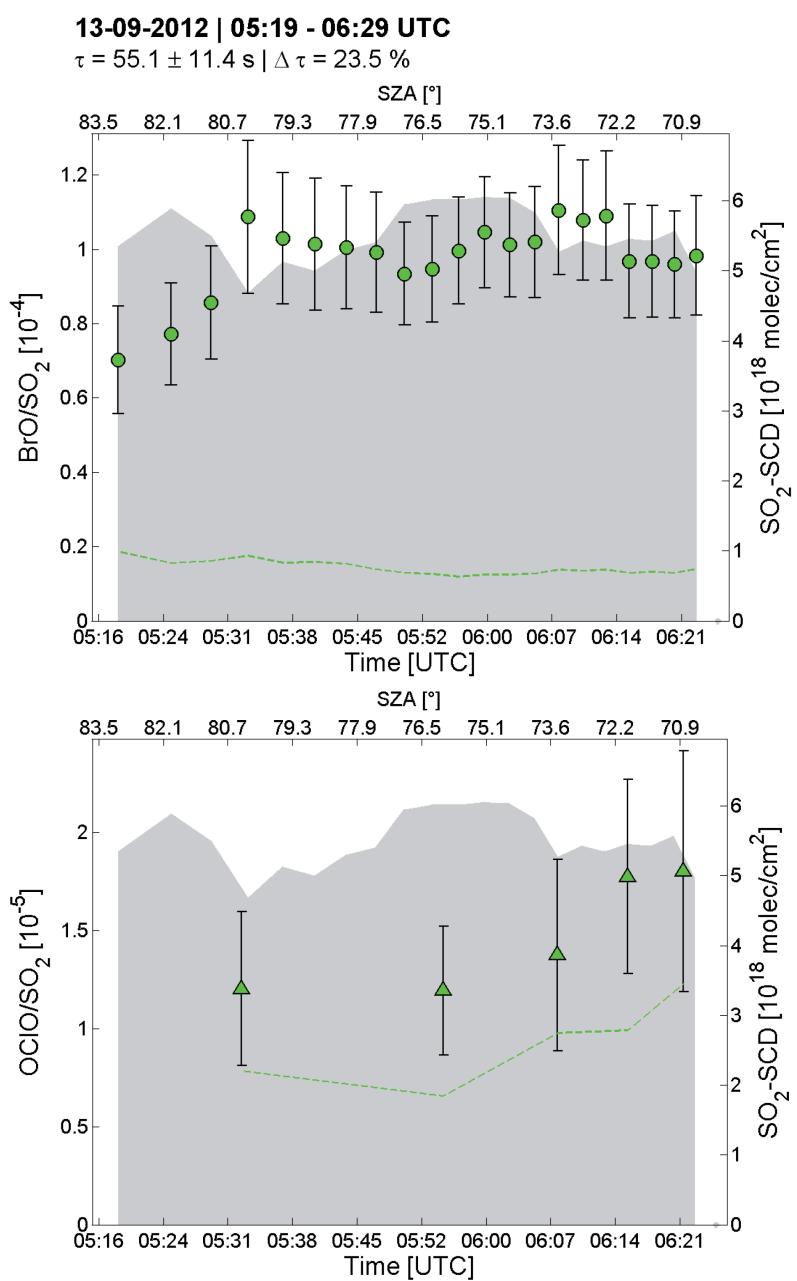

Figure 9. Early morning point measurement of $\mathrm{BrO}$ and $\mathrm{OClO}$ : the $\mathrm{BrO} / \mathrm{SO}_{2}$ ratio increases between 05:17 and 05:32 UTC (top), reaching a plateau afterwards. The corresponding $\mathrm{OClO} / \mathrm{SO}_{2}$ ratio also shows an increase which is delayed by approximately 30 40 min with respect to $\mathrm{BrO}$ (note that the $\mathrm{OClO} / \mathrm{SO}_{2}$ ratios of this scan were averaged to increase the detection sensitivity; see also Sect. 4.1.3).

direction and velocity) did not change significantly during the measurement which is important for the interpretation of these data. In the case of $\mathrm{BrO}$, this increase (at large SZAs) was only observable due to the correction for stratospheric $\mathrm{BrO}$ signals, where we assumed a constant stratospheric $\mathrm{BrO} \mathrm{VCD}$ of $V_{\text {str, } \mathrm{BrO}}=4.0 \times 10^{13}$ molecules $\mathrm{cm}^{-2}$ (see Sect. 3.9). However, according to Schofield et al. (2004), slight variations of about $10-20 \%$ in the stratospheric $\mathrm{BrO}$ load are to be expected during that time of day (i.e. $83.2>\mathrm{SZA}>80.3^{\circ}$ ). Hence, to ensure that the observed increase can be attributed to variations in the volcanic column (rather than stratospheric variations) we performed a sensitivity study for this data set by linearly varying the stratospheric VCD from 3.0 to $4.0 \times 10^{13}$ molecules $\mathrm{cm}^{-2}$ during the time span of the first five data points. This test did not reveal any significant change and still clearly showed the increasing trend of the $\mathrm{BrO} / \mathrm{SO}_{2}$ ratio before 05:32 UTC. This is mainly due to the comparatively strong volcanic $\mathrm{BrO}$ signal of several $10^{14}$ molecules $\mathrm{cm}^{-2}$ during this measurement. We attribute this observation to be a direct result of the increasing solar irradiance at that time of the day (i.e. the increasing photolysis of $\mathrm{Br}_{2}$ and $\mathrm{BrCl}$ molecules). This is further evidence that the availability of sunlight is an important parameter for the chemical processes related to the $\mathrm{BrO}$ and $\mathrm{OClO}$ formation in volcanic plumes. On 22 September 2012, a similar point measurement was performed slightly later in the morning between 06:33 and 06:48 UTC (at $\tau=7.6 \pm 1.6 \mathrm{~min}$ ). It showed a constant $\mathrm{BrO} / \mathrm{SO}_{2}$ ratio of $(1.15 \pm 0.2) \times 10^{-4}$ (20 spectra) which is in good agreement with the values shown in Fig. 9 after reaching the steady state. $\mathrm{OClO}$ could not be detected in this scan.

\subsubsection{BrO, $\mathrm{OClO}$ and $\mathrm{ClO}$ mixing ratios}

As described in Sect. 3.6, average $\mathrm{BrO}$ and $\mathrm{OClO}$ concentrations (volume number densities) were estimated from plume cross-section scans assuming a circular plume shape. The plume diameter could be estimated in 61 from a total of 90 cross-section scans performed during the campaign. Furthermore, $\mathrm{ClO}$ concentrations were calculated as described in Sect. 3.7. The corresponding number densities were converted into mixing ratios and the results are plotted in Fig. 10 as a function of the plume age $\tau$. Only $\mathrm{BrO}, \mathrm{ClO}$ and $\mathrm{OClO}$ concentrations above the detection limit were considered. Furthermore, only measurements during clear meteorological conditions were included to avoid potential impacts on the radiation light path, for instance caused by clouds or high background aerosol concentrations.

$\mathrm{BrO}$ mixing ratios between $11( \pm 7) \mathrm{ppt}$ and $2.7( \pm 1.2) \mathrm{ppb}$ were derived covering plume ages up to $17 \mathrm{~min}$. The largest values were found in the young plume following a decreasing trend due to plume dilution. The $\mathrm{OClO}$ mixing ratios ranged between $37( \pm 24)$ and $597( \pm 440) p p t$ and the corresponding values for $\mathrm{ClO}$ between $70( \pm 44)$ and $235( \pm 121)$ ppt. Both species could be detected up to $6 \mathrm{~min}$ downwind. Mean abundances in the young plume (i.e. $\tau<$ $4 \mathrm{~min}$ ) were $\overline{\mathrm{ClO}}=139 \pm 39 \mathrm{ppt}, \overline{\mathrm{BrO}}=1.35 \pm 0.45 \mathrm{ppb}$ and $\overline{\mathrm{OClO}}=300 \pm 90 \mathrm{ppt}$.

The comparatively large errors of the derived mixing ratios (see Fig. 10) are due to our conservative estimation of the SCD errors and the uncertainties in the plume diameter estimation. More detailed radiative transfer effects (e.g. multiple scattering, light dilution; for details see Kern et al., 2010; Kern et al., 2012) were neglected in the determination of the mixing ratios as well as potential deviations from the circular plume cross section. Hence, the reported numbers are rather an estimate of the order of magnitude of the average plume abundances of these species. Nonetheless, for the ob- 


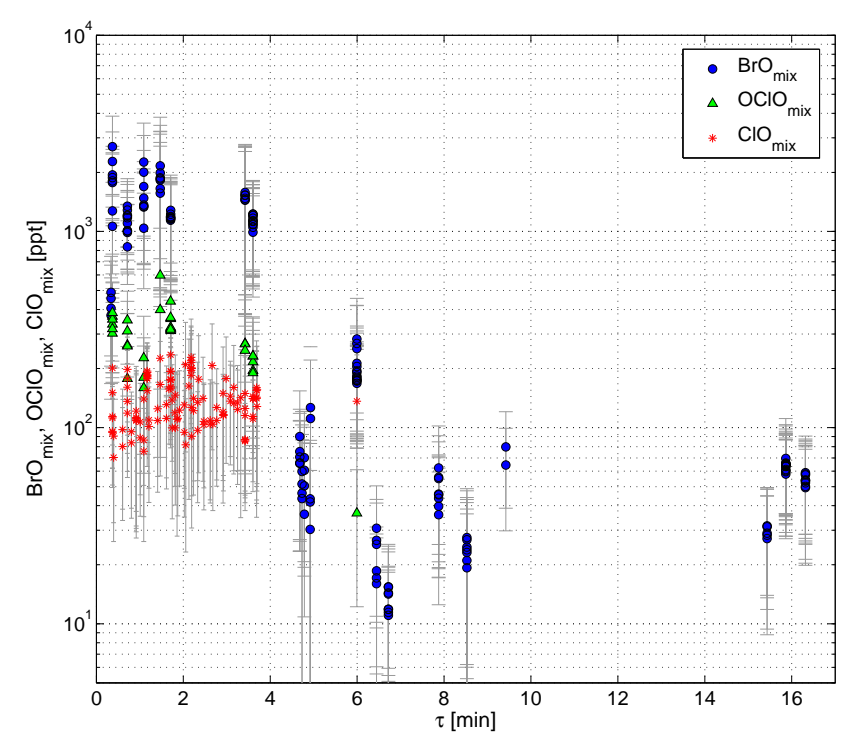

Figure 10. Mixing ratios of $\mathrm{ClO}, \mathrm{BrO}$ and $\mathrm{OClO}$ as a function of the plume age $\tau$. $\mathrm{BrO}$ and $\mathrm{OClO}$ mixing ratios were determined directly from the retrieved SCDs assuming a circular plume cross section. $\mathrm{ClO}$ mixing ratios were determined from the $\mathrm{BrO}$ and $\mathrm{OClO}$ SCDs assuming chemical equilibrium between the formation and destruction of OClO. $y$-axis error bars were derived using Gaussian error propagation of the DOAS fit errors and the uncertainties in the estimation of the plume diameter $(\mathrm{BrO}$ and $\mathrm{OClO})$. Values between 70 and $235( \pm 44-121)$ ppt $(\mathrm{ClO}), 11$ and $2700( \pm 7-1200)$ ppt $(\mathrm{BrO})$ and 37 and $597( \pm 24-440)$ ppt $(\mathrm{OClO})$ were found covering plume ages between 0 and $17 \mathrm{~min}$. Mean abundances in the young plume (i.e. $\tau<4$ min) were $\overline{\mathrm{ClO}}=139 \mathrm{ppt}, \overline{\mathrm{BrO}}=1.35 \mathrm{ppb}$ and $\overline{\mathrm{OClO}}=$ $300 \mathrm{ppt}$. Due to plume dispersion, the concentrations decrease with increasing plume age.

servatory data (11-13 September 2012, i.e. $\tau<4$ min range in Fig. 10) potential deviations due to RTE are most likely smaller than a factor of 2, relying on the findings of Kern et al. (2012) and Mori et al. (2006). This is due to the fairly good measurement conditions (i.e. low plume condensation, see e.g. Fig. 1) and furthermore because of the proximity to the plume (mean distance to plume: $\bar{d}=2.03 \mathrm{~km}, d_{\max }<$ $3.2 \mathrm{~km}$ ) and the high altitude at the measurement location (i.e. $2800 \mathrm{~m}$ a.s.l., lower scattering probability). Moreover, a strong eccentricity of the plume (i.e. pronounced elliptical plume shape) is unlikely in this plume age regime (see e.g. Turner, 1970).

The measurements performed in the aged plume (i.e. data points at $\tau>4 \mathrm{~min}$ in Fig. 10) are most likely stronger influenced by deviations from the assumed circular cross section and by the light dilution effect since they were partly performed at sea level and at greater plume distances (up to $17 \mathrm{~km}$ ). Thus, the observed decrease of the $\mathrm{BrO}$ mixing ratios in the ageing plume (see Fig. 10) is most likely not solely due to the decreasing concentrations (plume dilution) but is probably also influenced by light dilution and elliptical plume shapes. However, in most cases the latter two effects should counteract each other to a certain degree since light dilution induces a decrease in the "true" signal (i.e. the true signal is larger than the one derived from the measured SCDs), whereas for typical measurement geometries the lengths of the effective light paths $\left(l_{\mathrm{eff}, i}\right)$ through the plume are often underestimated (and thus the concentrations are overestimated). The latter is due to the pronounced elliptical shape of the plume (i.e. $\sigma_{\text {hor }}>\sigma_{\text {vert }}$, for typical conditions). At large plume viewing angles (i.e. close to the horizon) $\sigma_{\text {vert }}$ is estimated from the scan (assuming $\sigma_{\text {hor }}=\sigma_{\text {vert }}$ when using the method described in Sect. 3.6) and as a result the $l_{\mathrm{eff}, i}$ are underestimated if the plume cross section is elliptical. A rough estimation assuming slightly stable conditions (i.e. Pasquill stability class E, see e.g. Turner, 1970) would approximately yield a factor of $\sigma_{\text {vert }} / \sigma_{\text {hor }} \approx 0.16$ at $20 \mathrm{~km}$ distance from the source, yet the concentrations would be overestimated by up to a factor of 6 for the discussed measurement geometry (plume close to the horizon).

\subsection{Results for IO, OIO and OBrO}

We investigated the presence of IO (in the UV spectral range), $\mathrm{OIO}$ and $\mathrm{OBrO}$ (in the VIS spectral range) but did not detect any of these species. Here, we give both the detection limits for plume ages smaller and larger than $3 \mathrm{~min}$ (Table 3) since it appears reasonable to assume that these species - if abundant in the plume - show a similar plume evolution as was observed in the case of $\mathrm{BrO}$ and $\mathrm{OClO}$ (for details see Sect. 4.1.3). For plume ages larger than $3 \mathrm{~min}$, upper limits of $5.2 \times 10^{-6}\left(\mathrm{IO} / \mathrm{SO}_{2}\right), 2.8 \times 10^{-5}\left(\mathrm{OIO} / \mathrm{SO}_{2}\right)$ and $1.8 \times 10^{-5}\left(\mathrm{OBrO} / \mathrm{SO}_{2}\right)$ were found. Note that the UV spectrograph showed a better performance ( $S / N$ ratio) than the VIS spectrograph, which is indicated by the lower detection limits for IO compared to $\mathrm{OIO}$ and $\mathrm{OBrO}$.

\section{Conclusions}

Simultaneous $\mathrm{OClO}$ and $\mathrm{BrO}$ distributions were measured in the volcanic plume of Mt. Etna in September 2012 using the MAX-DOAS method. Measurements of volcanic OClO are still rare and most reports are merely based on a few data points. Our results provide new, very detailed insights into the chemical evolution of these species in the volcanic plume. For the first time, the formation of both $\mathrm{BrO}$ and $\mathrm{OClO}$ could be observed in a volcanic plume. These processes were studied in great detail and formation times of $\mathrm{BrO}$ and $\mathrm{OClO}$ (i.e. the time until an equilibrium is reached) between 2 and $3 \mathrm{~min}$ downwind of the craters were found. Furthermore, mean concentrations of the order of several hundred ppt $\left(\mathrm{ClO}_{y}\right.$, i.e. $\mathrm{ClO}, \mathrm{OClO})$ up to several ppb $(\mathrm{BrO})$ could be estimated. Keeping in mind that most of the $\mathrm{ClO}_{y}$ and $\mathrm{BrO}_{y}$ originates from the initially emitted $\mathrm{HCl}$ and $\mathrm{HBr}$, our findings strongly suggest that the oxidation of chloride is much weaker com- 
Table 3. Upper limits of IO, OIO and OBrO for the retrieved SCDs, the $\mathrm{X}_{m} \mathrm{O}_{n} / \mathrm{SO}_{2}$ ratios and the mixing ratios $\left(r_{i}\right)$. Note that the values do not correspond to the same plume spectrum but were determined individually.

\begin{tabular}{llll}
\hline Species & $\mathrm{SCD}\left[\mathrm{cm}^{-2}\right]$ & $\mathrm{X}_{m} \mathrm{O}_{n} / \mathrm{SO}_{2}$ & $r_{i}[\mathrm{ppt}]$ \\
\hline \multicolumn{4}{c}{ Plume age $\tau<3 \mathrm{~min}$} \\
\hline IO & $8.6 \times 10^{12}$ & $1.8 \times 10^{-6}$ & 29 \\
OIO & $7.8 \times 10^{13}$ & $2.0 \times 10^{-5}$ & 294 \\
OBrO & $4.5 \times 10^{13}$ & $1.1 \times 10^{-5}$ & 164 \\
\hline
\end{tabular}

Plume age $\tau>3 \mathrm{~min}$

\begin{tabular}{llll}
\hline IO & $7.6 \times 10^{12}$ & $5.2 \times 10^{-6}$ & 4 \\
OIO & $7.5 \times 10^{13}$ & $2.8 \times 10^{-5}$ & 25 \\
OBrO & $3.6 \times 10^{13}$ & $1.8 \times 10^{-5}$ & 12 \\
\hline
\end{tabular}

pared to the bromide equivalent. This is mainly due to the fact that any potential $\mathrm{Cl}$ release mechanisms are likely less efficient compared to bromine. Moreover, once formed, the $\mathrm{Cl}$ radicals in the plume will rapidly react with $\mathrm{CH}_{4}$, which may even cause a significant depletion of $\mathrm{CH}_{4}$ in the plume. This very important issue is addressed in the following, in which we use our results (i.e. the observed formation times of $\mathrm{ClO}_{y}$, see Sect. 4.1.3, and the estimation of mean concentrations, see Sect. 4.1.5) to derive an estimate of the $\mathrm{Cl}$ atom concentrations in the plume and, based on that, to investigate the potential of a chlorine-induced depletion of $\mathrm{CH}_{4}$ in the plume environment.

\section{Cl-atom concentrations and the depletion of atmospheric $\mathrm{CH}_{4}$ in the plume}

Once $\mathrm{Cl}$ atoms are produced in a volcanic plume, they will rapidly react either with $\mathrm{CH}_{4}$ or with $\mathrm{O}_{3}$ :

$$
\begin{aligned}
& \mathrm{Cl}+\mathrm{CH}_{4} \rightarrow \mathrm{HCl}+\mathrm{CH}_{3}, \\
& \mathrm{Cl}+\mathrm{O}_{3} \rightarrow \mathrm{ClO}+\mathrm{O}_{2} .
\end{aligned}
$$

The corresponding reaction rate coefficients are $k_{9}=$ $1.0 \times 10^{-13} \mathrm{~cm}^{3} \mathrm{~s}^{-1}$ (Reaction R9 at $298 \mathrm{~K}$ ) and $k_{10}=1.2 \times$ $10^{-11} \mathrm{~cm}^{3} \mathrm{~s}^{-1}$ (Reaction R10 at $298 \mathrm{~K}$; Sander et al., 2006). Note that Reaction (R9) is 16 times faster than the $\mathrm{OH}+\mathrm{CH}_{4}$ reaction (at $298 \mathrm{~K}$ ) and has a strong positive temperature dependence (Sander et al., 2006). All other $\mathrm{Cl}$ sink reactions are much slower and are therefore neglected here.

$\mathrm{Cl}$ atom concentrations in the plume were estimated using the $\mathrm{ClO}$ and $\mathrm{OClO}$ concentrations inferred from our measurements (see Sect. 4.1.5) and the corresponding young plume formation times $\tau_{0}$ (see Sect. 4.1.3). For the estimation we assumed that the total amount of $\mathrm{ClO}_{y}$ (i.e. $\left[\mathrm{ClO}_{y}\right]=$ $[\mathrm{ClO}]+[\mathrm{OClO}]$ ), observed after the levelling of OClO (i.e. at plume age $\tau_{0}$ ) was produced from $\mathrm{Cl}$ atoms via Reac-
Table 4. Retrieved Cl-atom concentrations (see Eq. 8) and the corresponding $\mathrm{CH}_{4}$ lifetimes $\left(\tau_{\mathrm{CH}_{4}}\right)$ according to Eq. (9). The values were determined for different background $\mathrm{O}_{3}$ concentrations to account for potentially depleted $\mathrm{O}_{3}$ in the plume.

\begin{tabular}{lll}
\hline $\mathrm{Cl}\left[\mathrm{cm}^{-3}\right]$ & $\tau_{\mathrm{CH}_{4}}$ & $\mathrm{O}_{3}[\mathrm{ppb}]$ \\
\hline $2.5 \times 10^{6}$ & $47 \mathrm{~d}$ & 80 \\
$5.0 \times 10^{6}$ & $23 \mathrm{~d}$ & 40 \\
$2.0 \times 10^{7}$ & $6 \mathrm{~d}$ & 10 \\
$2.0 \times 10^{8}$ & $14 \mathrm{~h}$ & 1 \\
\hline
\end{tabular}

tion $(\mathrm{R} 10)(\mathrm{ClO})$ and Reaction $(\mathrm{R} 7)(\mathrm{OClO})$. Assuming a linear increase of $\left[\mathrm{ClO}_{y}\right]$ the corresponding formation rate of $\mathrm{Cl}$ atoms was estimated as follows:

$$
\left(\frac{\mathrm{d}}{\mathrm{d} t}[\mathrm{Cl}]\right)_{\mathrm{obs}} \approx \frac{\mathrm{d}}{\mathrm{d} t}\left[\mathrm{ClO}_{y}\right] \approx \frac{\left[\mathrm{ClO}_{y}\right]\left(\tau=\tau_{0}\right)}{\tau_{0}} .
$$

Actually the true rate of $\mathrm{Cl}$ atom production $\mathrm{d} / \mathrm{d} t[\mathrm{Cl}]$ is larger since a fraction of the $\mathrm{Cl}$ atoms reacts with $\mathrm{CH}_{4}(\mathrm{Re}$ action R9) and never shows up as $\mathrm{ClO}_{y}$ (possible reaction of $\mathrm{Cl}$ with other hydrocarbons is likely to be unimportant and was therefore neglected here):

$$
\frac{\mathrm{d}}{\mathrm{d} t}[\mathrm{Cl}] \approx\left(\frac{\mathrm{d}}{\mathrm{d} t}[\mathrm{Cl}]\right)_{\mathrm{obs}} \times \frac{1}{K}
$$

with

$$
K=\frac{\left[\mathrm{O}_{3}\right] \times k_{10}}{\left[\mathrm{O}_{3}\right] \times k_{10}+\left[\mathrm{CH}_{4}\right] \times k_{9}} .
$$

The corresponding $\mathrm{Cl}$-atom concentration is then given by

$[\mathrm{Cl}]=\frac{\mathrm{d}}{\mathrm{d} t}[\mathrm{Cl}] \times \tau_{\mathrm{Cl}} \approx \frac{\mathrm{d}}{\mathrm{d} t}\left[\mathrm{ClO}_{y}\right] \times \frac{1}{K} \times \tau_{\mathrm{Cl}}$,

whereas the lifetime of $\mathrm{Cl}\left(\tau_{\mathrm{Cl}}\right)$ was estimated by

$\tau_{\mathrm{Cl}}=\frac{1}{\left[\mathrm{O}_{3}\right] \times k_{10}+\left[\mathrm{CH}_{4}\right] \times k_{9}}$.

Introducing the expression for $\tau_{\mathrm{Cl}}$ in Eq. (6) and using Eq. (3), an estimate of the $\mathrm{Cl}$-atom concentration can be obtained:

$[\mathrm{Cl}]=\frac{\frac{\mathrm{d}}{\mathrm{d} t}\left[\mathrm{ClO}_{y}\right]}{\left[\mathrm{O}_{3}\right] \times k_{10}} \approx \frac{\left[\mathrm{ClO}_{y}\right]}{\tau_{0} \times\left[\mathrm{O}_{3}\right] \times k_{10}}$.

Based on this the $\mathrm{CH}_{4}$ lifetime in the plume (due to reaction with $\mathrm{Cl}$, see Reaction $\mathrm{R} 9$ ) can be derived:

$\tau_{\mathrm{CH}_{4}} \approx \frac{1}{[\mathrm{Cl}] \times k_{9}} \approx \frac{\tau_{0} \times\left[\mathrm{O}_{3}\right] \times k_{10}}{\left[\mathrm{ClO}_{y}\right] \times k_{9}}$.

Note that $\tau_{0}$ denotes the formation time of $\mathrm{OClO}$ as introduced in Sect. 4.1.3, whereas $\tau_{\mathrm{CH}_{4}}$ corresponds to the methane lifetime in the plume. 
For the estimation of $\mathrm{ClO}_{y}$, we determined mean $\mathrm{ClO}$ and $\mathrm{OClO}$ concentrations from our retrieval considering only plume ages between 120 and $240 \mathrm{~s}$ (see also Sect. 4.1.5). We retrieved values of $\overline{\mathrm{ClO}}=2.0 \times 10^{9} \mathrm{~cm}^{-3}$ and $\overline{\mathrm{OClO}}=3.7 \times$ $10^{9} \mathrm{~cm}^{-3}$ respectively and hence $\overline{\mathrm{ClO}_{y}}=5.7 \times 10^{9} \mathrm{~cm}^{-3}$. Based on our findings discussed in Sect. 4.1.3 we estimated the $\mathrm{ClO}_{y}$ formation duration to be $\tau_{0}=142 \mathrm{~s}$. The $\mathrm{OClO}$ concentrations (used to estimate $\mathrm{ClO}_{y}$ ) might carry potential uncertainties due to RTE or non-circular plumes. However, as discussed in Sect. 4.1.5, these deviations should be small (i.e. $\lesssim 2$ ) for the majority of data points recorded in the young plume and should therefore not significantly influence the outcome of this analysis. The typical tropospheric $\mathrm{O}_{3}$ background is $60-80 \mathrm{ppb}$ for this (relatively polluted) region and altitude (Kalabokas et al., 2013). The expected $\mathrm{CH}_{4}$ lifetime in the plume is directly proportional to the prevailing $\mathrm{O}_{3}$ concentration (Eq. 9). Since $\mathrm{O}_{3}$ is most likely depleted in the plume (von Glasow, 2010; Kelly et al., 2013) we determined $[\mathrm{Cl}]$ and $\tau_{\mathrm{CH}_{4}}$ under variation of the $\mathrm{O}_{3}$ concentration (assuming $\mathrm{O}_{3}$ mixing ratios between 1 and $80 \mathrm{ppb}$ ). Our results are summarised in Table 4 and show relatively small Clatom concentrations (i.e. $10^{6}-10^{8} \mathrm{~cm}^{-3}$ ) and $\mathrm{CH}_{4}$ lifetimes between $14 \mathrm{~h}$ and up to 47 days. These lifetimes are more than 2 orders of magnitude shorter than the average atmospheric lifetime of $\mathrm{CH}_{4}$.
However, if $\mathrm{O}_{3}$ is not strongly depleted, $\mathrm{CH}_{4}$ destruction by $\mathrm{Cl}$ atoms will probably not lead to a detectable loss of $\mathrm{CH}_{4}$ in the plume since the $\mathrm{Cl}$ levels derived from our measurements (at plume age $\tau=142 \mathrm{~s}$ ) should decrease rapidly as the plume disperses. Even if these $\mathrm{Cl}$ levels would prevail for a few hours downwind, only a small fraction (less than $1 \%$ ) of the $\mathrm{CH}_{4}$ would be destroyed (assuming that the mean $\mathrm{O}_{3}$ levels in the plume exceed $10 \mathrm{ppb}$ ). However, in regions of very low $\mathrm{O}_{3}$ concentrations (i.e. possibly in the plume centre; von Glasow, 2010), a significant loss of $\mathrm{CH}_{4}$ could be present but the atmospheric impact would probably still be negligible since the effective volume of this potential methanedepleting environment would be very small. Nevertheless, we want to remark that our calculations are based on the volcanic conditions at Mt. Etna in September 2012, and we therefore want to stress that it is absolutely possible that $\mathrm{CH}_{4}$ depletion may become detectable in plumes of other volcanoes or at different conditions (e.g. due to varying volcanic activity, stronger chlorine emissions, larger $\mathrm{Cl}^{-} / \mathrm{Br}^{-}$ratios, low NMHC (non-methane hydrocarbons) concentrations or the presence of volcanic particles favouring the chloride oxidation). 


\section{Appendix A: Details regarding the data evaluation}

\section{A1 Details regarding the additional $R 4$ spectrum}

In addition to the standard ring spectrum (calculated using the software DOASIS; Kraus, 2006), a second ring spectrum $(R 4)$ was determined as follows (for details see Wagner et al., 2009, Appendix B therein):

$$
R 4(j)=R(j) \times\left(\frac{\lambda(j)}{\lambda_{0}}\right)^{4}-R(j) .
$$

Here, $j$ denotes the pixel on the detector, $\lambda(j)$ the appropriate wavelength and $\lambda_{0}$ the central wavelength of the evaluation range. $R(j)$ denotes the intensity of the ring spectrum at detector channel $j$. Note that the $R 4$ spectrum was orthonormalised with respect to $\lambda_{0}$.

The $R 4$ spectrum accounts for influences due to multiple scattering and/or scattering on aerosols and cloud particles which are not considered in the determination of $R$. Improvements due to the $R 4$ correction are discussed and visualised in Sect. A4 and in Fig. A2.

\section{A2 DOAS error treatment}

According to Stutz and Platt (1996) the error of atmospheric trace gas measurements with the DOAS technique does not purely arise from pure photon (shot) noise and is thus not entirely statistical (Poisson statistics). The fit residuals often show distinct structures which are mainly a result of the limited optical resolution of the instrument or due to uncertainties in the absorption spectra of the fitted species. In this case, the DOAS fit yields underestimated measures of the true fit uncertainty since the fitting routine is based on the assumption of individual radiance measurements in each pixel on the detector. Thus, in the case of structured fit residuals, this underestimation has to be accounted for. This can be done by multiplying the retrieved DOAS fit errors with a certain factor (here denoted with $U$ ) which can reach values of up to 6 according to Stutz and Platt (1996). The choice of $U$ for a given measurement is mainly dependent on the spectral width of the fitted absorption lines and on the width of potentially abundant residual structures (measured in channels on the detector; see Fig. 10 in Stutz and Platt, 1996). Since we could observe such residual structures in some of our measurements (see e.g. Fig. A2), we followed Stutz and Platt (1996) and corrected our retrieved DOAS fit errors with a factor of $U=4$. We remark that this constitutes a conservative estimation of the measurement uncertainty. Therefore, in the case of good fit results (i.e. low peak-to-peak value of the fit residual, $\bar{\Delta}_{\text {res }}$ ), this factor was reduced as follows:

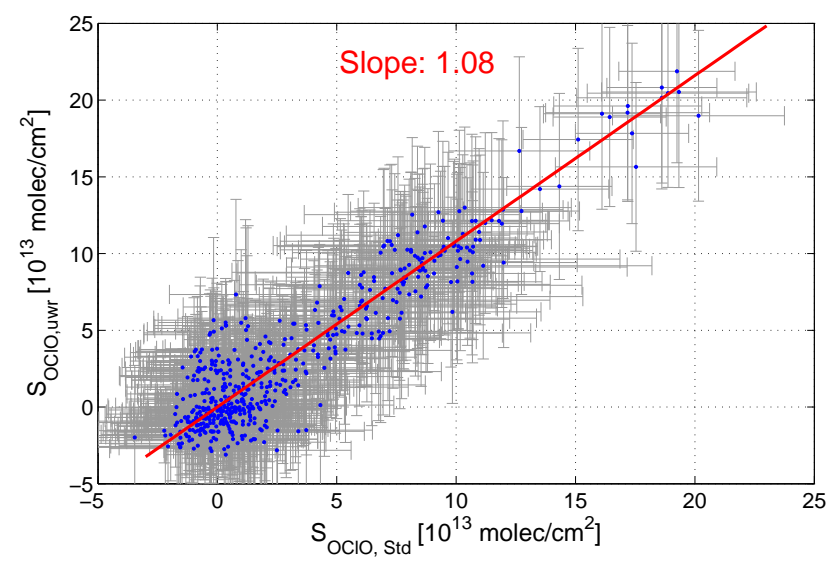

Figure A1. Retrieved OClO SCDs from the standard ("Std") evaluation range $\mathrm{OClO}_{\mathrm{Std}}(330.6-356.3 \mathrm{~nm})$ and the second "upper" wavelength range for the evaluation of $\mathrm{OClO}_{\mathrm{uwr}}(363.6-391.3 \mathrm{~nm})$. The values show good coincidence within their uncertainties with slightly larger SCDs $(\sim 8 \%)$ in the upper wavelength range.

(i)

$$
\begin{aligned}
& \bar{\Delta}_{\text {res }}>1.5 \times 10^{-3} \\
& \Rightarrow \quad U=4 \quad \text { (see e.g. Fig. A2), }
\end{aligned}
$$

(ii) $1.5 \times 10^{-3} \geq \bar{\Delta}_{\text {res }}>1.2 \times 10^{-3}$

$$
\Rightarrow \quad U=3.5 \text {, }
$$

(iii) $1.2 \times 10^{-3} \geq \bar{\Delta}_{\text {res }}$

$$
\Rightarrow \quad U=3 \quad \text { (see e.g. Fig. 4). }
$$

We found a good correlation between $\bar{\Delta}_{\text {res }}$ and the width of structures in the residual. However, we want to point out that this approach constitutes only a rough - but easy to implement and still conservative - implementation of the interpretation of the retrieved DOAS fit errors (e.g. Donovan et al., 2014 , used a fixed correction factor of $U=3$ for their $\mathrm{OClO}$ and $\mathrm{BrO}$ evaluation). In Fig. A2 such an example of a structured residual is shown (one residual structure is marked and has a width of $W \approx 20-30$ channels on the detector). Typical absorption lines of the fitted species cover between 15 and 30 channels on the detector of our spectrograph. Considering these typical widths, we decided to use fit correction factors between 3 and 4, based on the findings of Stutz and Platt (1996) (see especially Fig. 10 therein).

\section{A3 Alternative OClO evaluation routine $\left(\mathrm{OClO}^{\mathrm{uwr}}\right)$}

OClO was additionally evaluated in a second range between 363.6 and $391.3 \mathrm{~nm}$ covering three $\mathrm{OClO}$ absorption bands. Besides the two ring spectra and the FRS, reference spectra of $\mathrm{SO}_{2}, \mathrm{O}_{3}, \mathrm{O}_{4}$ and $\mathrm{NO}_{2}$ were additionally included. In principle, an advantage of this "upper" wavelength range should be that it is less influenced by potential cross correlations with $\mathrm{BrO}, \mathrm{O}_{3}$ or $\mathrm{CH}_{2} \mathrm{O}$ in the DOAS fit. However, it was 

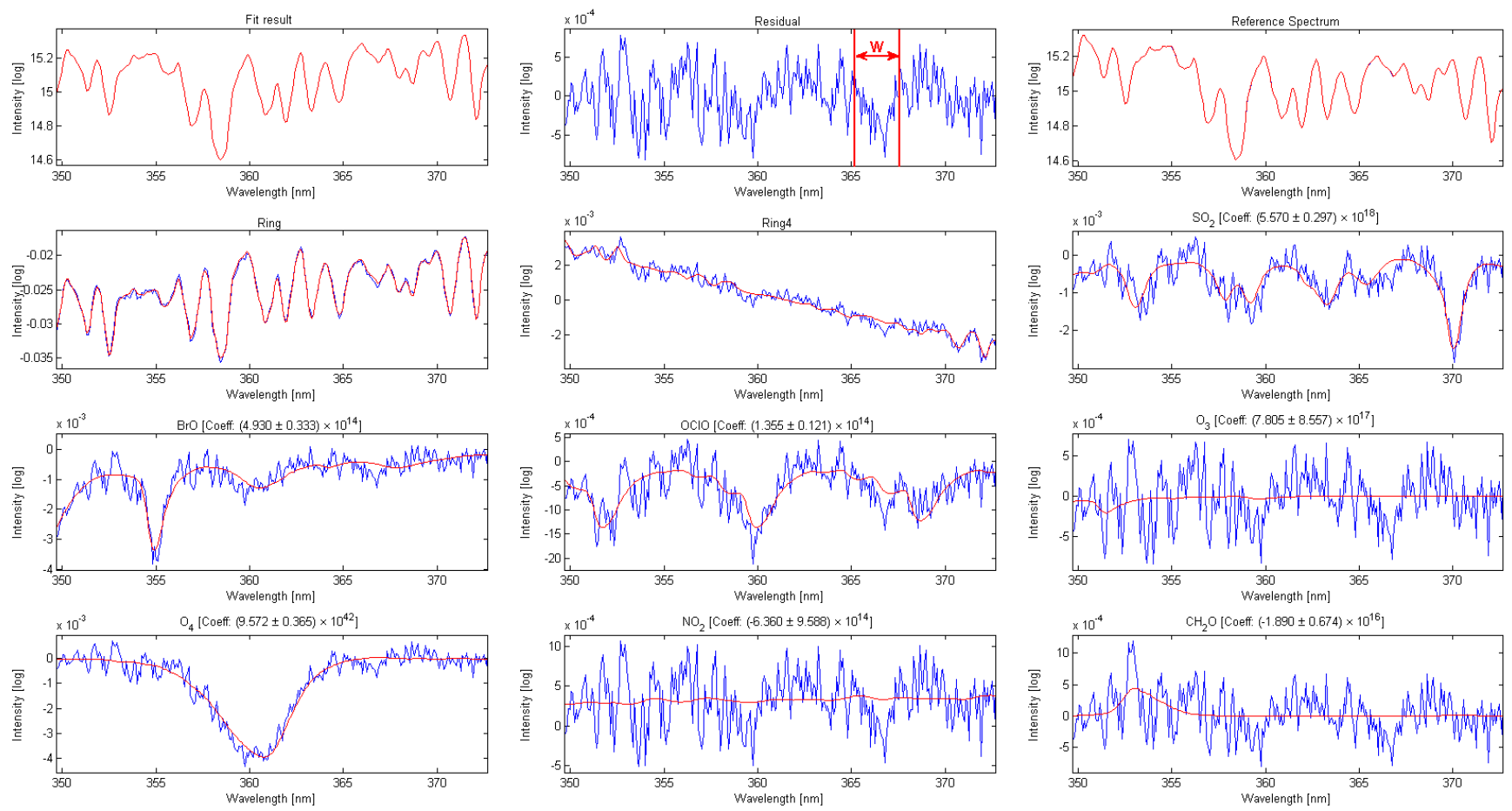

Figure A2. Exemplary fit result for the $\mathrm{SO}_{2}$ upper evaluation range between 349.8 and $372.8 \mathrm{~nm}$. The corresponding plume spectrum was recorded at the Etna observatory on 13 September 2012, 06:20 UTC, showing a $\mathrm{SO}_{2} \mathrm{SCD}$ of $S_{\mathrm{SO}_{2}}=5.57 \times 10^{18}$ molecules cm ${ }^{-2}$. In addition, the fit results of the two ring spectra $(R, R 4)$ and the additionally included absorbers $\left(\mathrm{SO}_{2}, \mathrm{O}_{3}, \mathrm{O}_{4}, \mathrm{NO}_{2}, \mathrm{H}_{2} \mathrm{CO}\right)$ are shown as well as the corresponding residual (peak-to-peak value: $\bar{\Delta}_{\text {res }}=1.60 \times 10^{-3}, \chi^{2}=3.00 \times 10^{-5}$ ). In this example, the residual is rather structured and one typical structure was marked showing a width $\mathrm{W}$ between 20 and 30 channels on the detector. Please note that $\mathrm{CH}_{2} \mathrm{O}$ was falsely detected in this fit (considering the fit error) due to the relatively structured residual. This shows the importance of the used fit correction factors $U$. Please also note the improvements due to the fitted $R 4$ spectrum, which are discussed in more detail in the text in Sect. A4.

found that the fits often showed distinct residual structures in this wavelength range, resulting in relatively large fit uncertainties compared to the standard evaluation range for $\mathrm{OClO}$ (Sect. 3.5.1). These structures are most likely caused by distinct solar Fraunhofer lines present in this wavelength region which can cause a strong ring effect. Nevertheless, the retrieved OClO SCDs show a good correlation with slightly larger SCDs $(\approx 8 \%)$ in the upper wavelength range (see Fig. A1).

\section{A4 Details regarding the $\mathrm{SO}_{2}$ evaluation}

$\mathrm{SO}_{2}$ was evaluated in two wavelength ranges in order to account for radiative transfer effects due to strong absorption at large $\mathrm{SO}_{2}$ column amounts in the wavelength regime below $320 \mathrm{~nm}$. An exemplary fit result of the $\mathrm{SO}_{2}$ evaluation in the alternative "upper" $\mathrm{SO}_{2}$ range $\left(\Delta \lambda_{\mathrm{SO}_{2}}\right.$,uwr $=349.8-$ $372.8 \mathrm{~nm}$ ) is shown in Fig. A2 showing a comparatively large $\mathrm{SO}_{2} \mathrm{SCD}$ of $S_{\mathrm{SO}_{2} \text {,uwr }}=5.57 \times 10^{18}$ molecules $\mathrm{cm}^{-2}$. The corresponding $\mathrm{SO}_{2} \mathrm{SCD}$ in the lower evaluation range was found to be smaller (as expected) and amounts to $\mathrm{S}_{\mathrm{SO}_{2} \text {, lwr }}=$ $4.89 \times 10^{18}$ molecules $\mathrm{cm}^{-2}$. The corresponding plume spectrum was recorded during the early morning point measure- ment discussed in Sect. 4.1.4 at 06:20 UTC on 13 September 2012. The FRS was recorded subsequently at 06:25 UTC, explaining the low $\mathrm{O}_{3} \mathrm{SCD}$. This example clearly shows the necessity of our conservative approach for the fit error estimation: in contrast to the $\mathrm{BrO}$ and $\mathrm{OClO}$ fit example (given in Sect. 3.4, Fig. 4), this fit example shows a rather structured fit residual (most likely due to the strong ring effect in this spectrum). This even causes a "false" detection of $\mathrm{CH}_{2} \mathrm{O}$ in this spectrum, showing a negative (but significant) SCD of $S_{\mathrm{CH}_{2} \mathrm{O}}=-1.89 \pm 0.67 \times 10^{16}$ molecules $\mathrm{cm}^{-2}$ (i.e. $\mathrm{CH}_{2} \mathrm{O}$ could not be detected in the standard evaluation range in this spectrum). Hence, using only the uncorrected DOAS fit error would yield a significant detection of $\mathrm{CH}_{2} \mathrm{O}$ in this case (even within $3 \sigma$ confidence). This demonstrates the tremendous importance of applying appropriate fit correction factors to account for these effects (as discussed in Sect. A2). The example given in Fig. A2 also clearly shows the significance of the $\lambda^{-4}$ dependency of the ring effect due to the relatively strong ring signal (i.e. ring optical densities of the order of $10^{-2}$ ), accounted for by fitting the $R 4$ spectrum (Sect. A1). Here, the $R 4$ correction leads to a fit improvement of $25 \%$ in the $\chi^{2}$ of fit residual ( $\chi^{2}$ is reduced from $4.02 \times 10^{-5}$ to $3.00 \times 10^{-5}$ ) and furthermore to a reduction 
in the total residual amplitude (i.e. peak-to-peak value) by $33 \%$ compared to the same fit excluding the $R 4$ spectrum (i.e. $\bar{\Delta}_{\text {res }}: 2.39 \times 10^{-3} \stackrel{R 4}{\longrightarrow} 1.60 \times 10^{-3}$ ).

Figure A3 shows a scatter plot of the retrieved $\mathrm{SO}_{2} \mathrm{SCDs}$ in both evaluation ranges. The retrieved values show good coincidence within their errors up to $\mathrm{SO}_{2} \mathrm{SCDs}$ around $4 \times 10^{18}$ molecules $\mathrm{cm}^{-2}$. For larger SCDs the trend starts to flatten due to the underestimated SCDs in the lower evaluation range.

\section{A5 Uncertainties and simplifications in the plume age determination}

The main uncertainties related to the plume age determination using Eq. (2) are due to uncertainties in the wind velocity and the determination of $l$ (i.e. mainly due to uncertainties in $\delta$ and $\alpha$, see Fig. 5). We thus subdivided our error-representation of the plume age $\tau$ into two contributions. The first (in the following denoted as $\Delta \tau_{l}(\alpha, \delta)$ ) is determined from the uncertainties in $\alpha$ and $\delta$ (mainly geometrical uncertainties). $\Delta \tau_{l}(\alpha, \delta)$ can vary strongly between different spectra from plume evolution scans due to the nature of the trigonometric functions involved in the calculation of $l . \Delta \tau_{l}(\alpha, \delta)$ is therefore plotted for each spectrum separately in form of $x$-axis error bars (see e.g. Fig. 7). The second contribution (in the following denoted as $\Delta \tau$ ) to the plume age error is caused by uncertainties in the wind velocity $\Delta v_{\text {wind }}$ which have a linear effect on the plume age uncertainty $\left(\partial \tau / \partial v_{\text {wind }} \propto \Delta v_{\text {wind }}\right)$. Since $\Delta \tau$ is independent of the measurement and plume angles, its relative impact on each spectrum $(\Delta \tau / \tau)$ is constant. The corresponding contribution is therefore given as a percentage value in the plot header (see e.g. Fig. 7).

For simplicity, we reduced the determination of $\tau$ to a 2-D problem in the horizontal plane, because differences in the altitude between plume and DOAS instrument have only a small influence on the determination of $\tau$ for typical scanning geometries (and a wind driven, horizontal plume propagation).

Furthermore, by reducing the volcanic plume and the telescopes viewing direction to a line (dotted lines in Fig. 5) we did not consider any effects caused by plume dispersion or the telescope's field of view for our estimation of $\tau$. These effects are usually negligible for typical scan geometries $\left(\varphi \approx 90^{\circ}\right.$, see Fig. 5) and may need to be considered when the measurements are performed at small angles $\varphi$. In this case the analysed light has penetrated a multiple of different plume ages which essentially causes a smoothing of the signal with respect to $\tau$. The corresponding impact regarding the interpretation of the data both depends on the desired temporal resolution of the respective scan (i.e. $\Delta \tau$ between individual scan spectra) and on the chemical variability of the analysed species in the analysed plume age range.

A further simplification in our algorithm is the reduction of the four main craters (BN, VOR, NE and SE) to

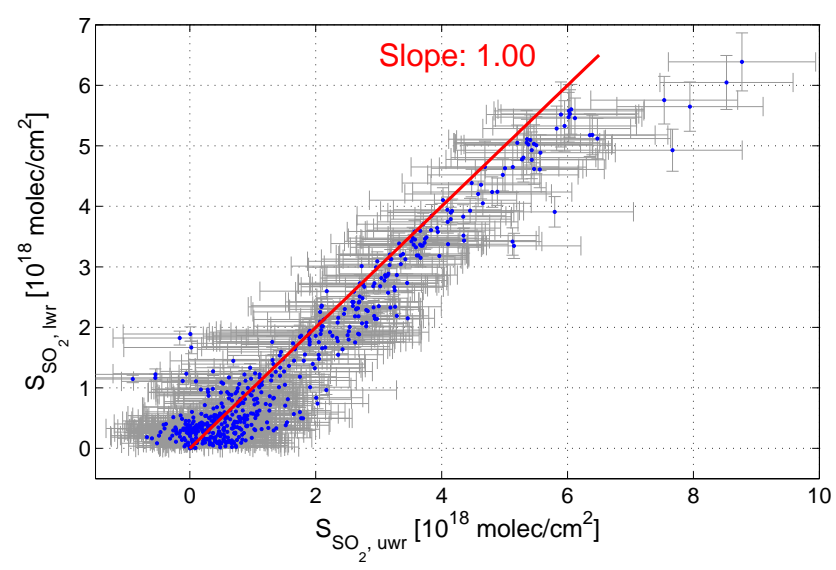

Figure A3. Retrieved $\mathrm{SO}_{2} \mathrm{SCD}$ from the two $\mathrm{SO}_{2}$ evaluation ranges. The evaluation scheme centred around $360 \mathrm{~nm}\left(\mathrm{SO}_{2, \mathrm{uwr}}\right)$ is plotted on the $x$ axis, while the scheme centred around $320 \mathrm{~nm}$ $\left(\mathrm{SO}_{2,1 \mathrm{wr}}\right)$ is on the $y$ axis. The red line indicates perfect correlation between both ranges. In the case of large $\mathrm{SO}_{2} \mathrm{SCDs}$ (i.e. $S_{\mathrm{SO}_{2}}>3 \times 10^{18}$ molecules $\mathrm{cm}^{-2}$ ), the retrieved SCDs in the lwrrange are increasingly underestimated.

a single emission source point $\boldsymbol{P}_{0}$ (i.e. $\tau=0$ point) located at $37^{\circ} 45^{\prime} 6.7^{\prime \prime} \mathrm{N}, 14^{\circ} 59^{\prime} 49.6^{\prime \prime} \mathrm{E}$ between the central craters (BN, VOR) and NE.

Furthermore, chemical processes which may have already taken place within the craters are also not considered in our routine. The latter effect can cause a plume age offset with respect to $\boldsymbol{P}_{0}$. Both effects are strongest for viewing directions close to the vent where the plumes are still separated. However, in most cases the corresponding error was assessed to be relatively small considering the uncertainties in the meteorological data.

\section{A6 Correction algorithm for stratospheric $\mathrm{BrO}$}

The BrO SCDs $\left(S_{\text {meas }}\right)$ derived from the DOAS evaluation (see Sect. 3.4) are composed of a volcanic ( $\left.S_{\text {plume }}\right)$ and a stratospheric contribution $\left(\mathrm{d} S_{\text {str }}\right)$. The latter is due to changes in the zenith angle $(\Theta)$ between plume spectrum and FRS.

$S_{\text {plume }}=S_{\text {meas }}-\mathrm{d} S_{\text {str }}$

In order to examine $\mathrm{d} S_{\text {str }}$ we used a simple geometrical approach assuming that the stratospheric AMF $X$ is given by $X=\cos (\Theta)^{-1}$ (see also Hönninger et al., 2004). For our purposes, this assumption was assessed to be sufficient, since plume spectra and FRS were recorded close in time and the SZAs were in most cases $(99.1 \%)$ smaller than $80^{\circ}$. For a more accurate estimation of the AMF, radiative transfer calculations are necessary.

The AMF relates the stratospheric slant column $S_{\mathrm{str}, i}$ of a given spectrum $i$ to the corresponding vertical column $V_{\text {str }}: S_{\mathrm{str}, i}=V_{\mathrm{str}} / \cos \left(\Theta_{i}\right)$. Based on this, the corresponding stratospheric contribution $\mathrm{d} S_{\mathrm{str}, i j}$ between two spectra $i, j$ 
can be determined from the vertical column and the difference in the AMF:

$\mathrm{d} S_{\mathrm{str}, i j}=V_{\text {str }} \times\left(\frac{1}{\cos \left(\Theta_{i}\right)}-\frac{1}{\cos \left(\Theta_{j}\right)}\right) \stackrel{\text { def }}{=} V_{\text {str }} \times \gamma_{i j}$.

Inserting Eq. (A3) into Eq. (A2) yields the following relation for the corresponding volcanic $\mathrm{BrO}$ column:

$S_{\text {plume }}=S_{\text {meas }}-V_{\text {str, BrO }} \times \gamma_{i j}$.

Following the results published by Sinnhuber et al. (2005) and Schofield et al. (2004) we assumed a constant stratospheric BrO column of $V_{\mathrm{str}, \mathrm{BrO}}=4.0 \times 10^{13}$ molecules $\mathrm{cm}^{-2}$ for our correction. Large diurnal variations in the stratospheric $\mathrm{BrO}$ column are unlikely for the SZA range covered by our data set $\left(\Theta<83^{\circ}\right)$. Thus, all retrieved $\mathrm{BrO}$ columns were corrected using Eq. (A4). The relative percentage impact (i.e. $\mathrm{d} S_{\text {str }} / S_{\text {meas }}$ ) of stratospheric signals on our $\mathrm{BrO}$ retrieval is visualised in Fig. A4.

Of course, the relative impact of the stratospheric contribution increases for smaller (measured) BrO SCDs (compare e.g. dark blue with green colours in Fig. A4). For BrO $\mathrm{SCDs}$ of the order of $6 \times 10^{14}$ molecules $\mathrm{cm}^{-2}$ (green colours) we found that the impact of $\mathrm{d} S_{\text {str }}$ on the measured signal amounts to $a=6.6 \% / \gamma_{i j}$ (linear regression in Fig. A4).

In order to estimate the influence of potential variations in the total stratospheric $\mathrm{BrO}$ load $\left(V_{\mathrm{str}, \mathrm{BrO}}\right)$, we additionally determined this slope for two different stratospheric BrO VCDs of $V_{\text {str, } \mathrm{BrO}}=2 \times 10^{13}$ and $V_{\mathrm{str}, \mathrm{BrO}}=7 \times$ $10^{13}$ molecules $\mathrm{cm}^{-2}$.

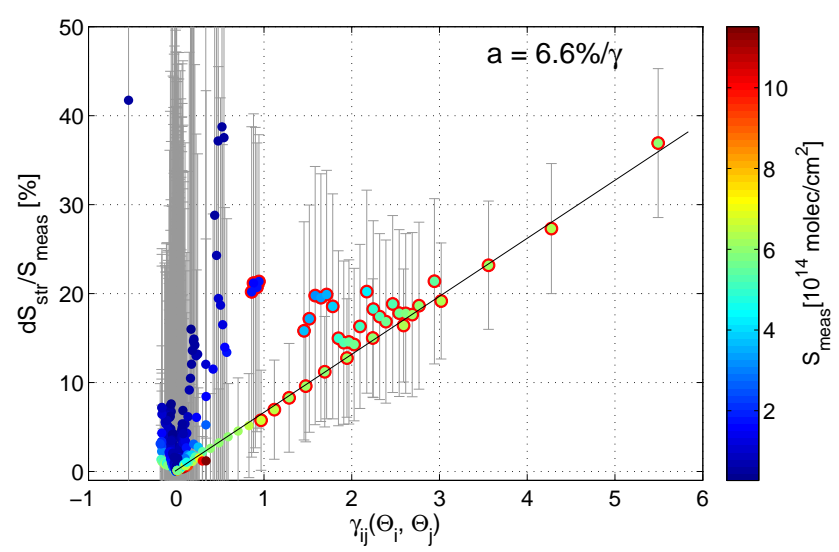

Figure A4. Relative deviation ( $\left.\mathrm{d} S_{\mathrm{str}} / S_{\text {meas }}\right)$ of volcanic BrO from the measured SCDs ( $S_{\text {meas }}$, colour-coded) due to stratospheric $\mathrm{BrO}$ differential SCDs. We assumed a vertical stratospheric $\mathrm{BrO}$ column of $V_{\text {str, } \mathrm{BrO}}=4.0 \times 10^{13}$ molecules $\mathrm{cm}^{-2}$. The results are plotted as a function of $\gamma_{i j}\left(\Theta_{i}, \Theta_{j}\right)$ (i.e. $\triangle$ SZA, see Eq. A4). We included all spectra from our data set with significant BrO SCDs corresponding to the respective detection limit. For $8 \%$ of the data, the stratospheric contribution $\left(\mathrm{d} S_{\text {str }}\right)$ exceeded the corresponding fit error (marked with red circles). All of these cases were observed at $\gamma_{i j}$ values exceeding 0.86 ; the corresponding measurements were performed before $08: 15$ or after 16:45 LT.

The corresponding impacts were $a=3.4 \% / \gamma_{i j}$ and $a=$ $11.8 \% / \gamma_{i j}$ respectively. This shows that influences due to stratospheric $\mathrm{BrO}$ are in most cases relatively small (i.e. for small $\gamma_{i j}$ values) even for considerably large stratospheric VCDs. Nonetheless, one has to keep in mind that these slopes were determined at considerably large $\mathrm{BrO}$ levels of the order of $S_{\text {meas }}=6 \times 10^{14}$ molecules $\mathrm{cm}^{-2}$. For lower measured BrO SCDs (blue colours in Fig. A4) the impact of stratospheric BrO increases and can significantly influence the volcanic signal, especially at large differences in the SZA between plume spectrum and FRS (i.e. at large $\gamma_{i j}$ values). 
Acknowledgements. We like to thank Henning Finkenzeller, Marco Huwe and Constantin Mayer for helpful discussions and for their great help with preparing and conducting the field campaign at Mt. Etna. Parts of the data presented in this work were obtained during the "Etna - Pizzi Deneri field trip" organised and supported by the Università degli Studi di Palermo (DiSTeM) and the Instituto Nazionale di Geofisica e Vulcanologia (INGV) of Catania and Palermo. We would furthermore like to thank Evelyn Jäkel for the determination of the OClO photolysis. We thank Udo Frieß for providing and further developing the software package MS-DOAS. Furthermore, we would like to thank Robert Holla, Johannes Zielcke, Stefan Schmidt, Martin Horbanski and Peter Lübcke for their great practical and theoretical support before and after the field campaign. We also thank the workshop crew of the Institute of Environmental Physics for their support in completing the instrument. J. Gliß and N. Bobrowski thank for the financial support from the DFG project "DFG BO 3611/1-1". Furthermore, we wish to thank the Editor J. Ma and three anonymous referees for their comments and helpful suggestions during the review process.

Edited by: J. Ma

\section{References}

Aiuppa, A., Inguaggiato, S., McGonigle, A., O’Dwyer, M., Oppenheimer, C., Padgett, M., Rouwet, D., and Valenza, M.: $\mathrm{H}_{2} \mathrm{~S}$ fluxes from Mt. Etna, Stromboli, and Vulcano (Italy) and implications for the sulfur budget at volcanoes, Geochim. Cosmochim. Ac., 69, 1861-1871, doi:10.1016/j.gca.2004.09.018, 2005.

Barrie, L. A., Bottenheim, J. W., Schnell, R. C., Crutzen, P. J., and Rasmussen, R. A.: Ozone destruction and photochemical reactions at polar sunrise in the lower Arctic atmosphere, Nature, 334, 138-141, doi:10.1038/334138a0, 1988.

Beirle, S., Hörmann, C., Penning de Vries, M., Dörner, S., Kern, C., and Wagner, T.: Estimating the volcanic emission rate and atmospheric lifetime of $\mathrm{SO}_{2}$ from space: a case study for Kīlauea volcano, Hawai ‘i, Atmos. Chem. Phys., 14, 8309-8322, doi:10.5194/acp-14-8309-2014, 2014.

Birks, J. W., Shoemaker, B., Leck, T. J., Borders, R. A., and Hart, L. J.: Studies of reactions of importance in the stratosphere, II. Reactions involving chlorine nitrate and chlorine dioxide, J. Chem. Phys., 66, 4591-4599, doi:10.1063/1.433716, 1977.

Bobrowski, N. and Giuffrida, G.: Bromine monoxide/sulphur dioxide ratios in relation to volcanological observations at Mt. Etna 2006-2009, Solid Earth, 3, 433-445, doi:10.5194/se-3-4332012, 2012.

Bobrowski, N. and Platt, U.: $\mathrm{SO}_{2} / \mathrm{BrO}$ ratios studied in five volcanic plumes, J. Volcanol. Geoth. Res., 166, 147-160, doi:10.1016/j.jvolgeores.2007.07.003, 2007.

Bobrowski, N., Hönninger, G., Galle, B., and Platt, U.: Detection of bromine monoxide in a volcanic plume, NATURE, 423, 273276, doi:10.1038/nature01625, 2003.

Bobrowski, N., von Glasow, R., Aiuppa, A., Inguaggiato, S., Louban, I., Ibrahim, O. W., and Platt, U.: Reactive halogen chemistry in volcanic plumes, J. Geophys. Res.-Atmos., 112, D06311, doi:10.1029/2006JD007206, 2007.

Bobrowski, N., Kern, C., Platt, U., Hörmann, C., and Wagner, T.: Novel $\mathrm{SO}_{2}$ spectral evaluation scheme using the 360
$390 \mathrm{~nm}$ wavelength range, Atmos. Meas. Tech., 3, 879-891, doi:10.5194/amt-3-879-2010, 2010.

Bogumil, K., Orphal, J., Homann, T., Voigt, S., Spietz, P., Fleischmann, O., Vogel, A., Hartmann, M., Kromminga, H., Bovensmann, H., Frerick, J., and Burrows, J.: Measurements of molecular absorption spectra with the SCIAMACHY pre-flight model: instrument characterization and reference data for atmospheric remote-sensing in the 230-2380 nm region, J. Photoch. Photobio. A, 157, 167-184, doi:10.1016/S1010-6030(03)00062-5, 2003.

Burrows, J., Richter, A., Dehn, A., Deters, B., Himmelmann, S., and Orphal, J.: Atmospheric remote-sensing reference data from GOME-2, temperature-dependent absorption cross sections of $\mathrm{O}_{3}$ in the 231-794 nm range, J. Quant. Spectrosc. Ra., 61, 509517, doi:10.1016/S0022-4073(98)00037-5, 1999.

Carroll, M. R. and Holloway, J. R.: Volatiles in magmas, Mineralogical Society of America, http://www.minsocam.org/msa/rim/ Rim30.html (last access: 29 September 2014), ISBN 0-93995036-7ISBN13 978-0-939950-36-2, 517 pp., 1994.

Chance, K. and Kurucz, R.: An improved high-resolution solar reference spectrum for earth's atmosphere measurements in the ultraviolet, visible, and near infrared, J. Quant. Spectrosc. Ra., 111, 1289-1295, doi:10.1016/j.jqsrt.2010.01.036, 2010.

Donovan, A., Tsanev, V., Oppenheimer, C., and Edmonds, M.: Reactive halogens $(\mathrm{BrO}$ and $\mathrm{OClO})$ detected in the plume of Soufrière Hills Volcano during an eruption hiatus, Geochem. Geophy. Geosy., 15, 3346-3363, doi:10.1002/2014GC005419, 2014.

Fickert, S., Adams, J. W., and Crowley, J. N.: Activation of $\mathrm{Br}_{2}$ and $\mathrm{BrCl}$ via uptake of $\mathrm{HOBr}$ onto aqueous salt solutions, J. Geophys. Res.-Atmos., 104, 23719-23727, doi:10.1029/1999JD900359, 1999.

Fleischmann, O. C., Meyer-Arnek, J., Burrows, J. P., and Orphal, J.: The Visible Absorption Spectrum of OBrO, Investigated by Fourier Transform Spectroscopy, J. Phys. Chem. A, 109, 50935103, doi:10.1021/jp044911x, 2005.

Francis, P., Maciejewski, A., Oppenheimer, C., Chaffin, C., and Caltabiano, T.: $\mathrm{SO}_{2}: \mathrm{HCl}$ ratios in the plumes from Mt. Etna and Vulcano determined by Fourier Transform Spectroscopy, Geophys. Res. Lett., 22, 1717-1720, doi:10.1029/95GL01657, 1995

General, S., Bobrowski, N., Pöhler, D., Weber, K., Fischer, C., and Platt, U.: Airborne I-DOAS measurements at Mt. Etna: BrO and $\mathrm{OClO}$ evolution in the plume, J. Volcanol. Geoth. Res., doi:10.1016/j.jvolgeores.2014.05.012, in press, 2015.

Gerlach, T.: Volcanic sources of tropospheric ozone-depleting trace gases, Geochem. Geophy. Geosy., 5, Q09007, doi:10.1029/2004GC000747, 2004.

Greenblatt, G. D., Orlando, J. J., Burkholder, J. B., and Ravishankara, A. R.: Absorption measurements of oxygen between 330 and $1140 \mathrm{~nm}$, J. Geophys. Res.-Atmos., 95, 18577-18582, doi:10.1029/JD095iD11p18577, 1990.

Hermans, C., A. C., V., Fally, S., Carleer, M., Colin, R., Coquart, B., Jenouvrier, A., and Merienne, M.-F.: Absorption cross-section of the collision-induced bands of oxygen from the UV to the NIR, Proceedings of the NATO Advanced Research Workshop, Weakly Interacting Molecular Pairs: Unconventional Absorbers of Radiation in the Atmosphere, France, 24 April-2 May 2002, NATO Science Series IV Earth and Environmental Sciences, 27, 193-202, available at: http://www.aeronomie.be/spectrolab/o2. htm (last access: 2 May 2015), 2003. 
Hermans, C., Vandaele, A., and Fally, S.: Fourier transform measurements of $\mathrm{SO}_{2}$ absorption cross sections: I. Temperature dependence in the $24000-29000 \mathrm{~cm}^{-1}$ (345$420 \mathrm{~nm}$ ) region, J. Quant. Spectrosc. Ra., 110, 756-765, doi:10.1016/j.jqsrt.2009.01.031, 2009.

Hönninger, G., von Friedeburg, C., and Platt, U.: Multi axis differential optical absorption spectroscopy (MAX-DOAS), Atmos. Chem. Phys., 4, 231-254, doi:10.5194/acp-4-231-2004, 2004.

Hörmann, C., Sihler, H., Bobrowski, N., Beirle, S., Penning de Vries, M., Platt, U., and Wagner, T.: Systematic investigation of bromine monoxide in volcanic plumes from space by using the GOME-2 instrument, Atmos. Chem. Phys., 13, 4749-4781, doi:10.5194/acp-13-4749-2013, 2013.

Jaeschke, W., Berresheim, H., and Georgii, H.-W.: Sulfur emissions from Mt. Etna, J. Geophys. Res.-Oceans, 87, 7253-7261, doi:10.1029/JC087iC09p07253, 1982.

Kalabokas, P. D., Cammas, J.- P., Thouret, V., Volz-Thomas, A., Boulanger, D., and Repapis, C. C.: Examination of the atmospheric conditions associated with high and low summer ozone levels in the lower troposphere over the eastern Mediterranean, Atmos. Chem. Phys., 13, 10339-10352, doi:10.5194/acp-1310339-2013, 2013.

Kelly, P. J., Kern, C., Roberts, T. J., Lopez, T., Werner, C., and Aiuppa, A.: Rapid chemical evolution of tropospheric volcanic emissions from Redoubt Volcano, Alaska, based on observations of ozone and halogen-containing gases, the 2009 Eruption of Redoubt Volcano, Alaska, J. Volcanol. Geoth. Res., 259, 317-333, doi:10.1016/j.jvolgeores.2012.04.023, 2013.

Kern, C., Sihler, H., Vogel, L., Rivera, C., Herrera, M., and Platt, U.: Halogen oxide measurements at Masaya Volcano, Nicaragua using active long path differential optical absorption spectroscopy, B. Volcanol., 71, 659-670, doi:10.1007/s00445008-0252-8, 2009.

Kern, C., Deutschmann, T., Vogel, L., Woehrbach, M., Wagner, T., and Platt, U.: Radiative transfer corrections for accurate spectroscopic measurements of volcanic gas emissions, B. Volcanol., 72, 233-247, doi:10.1007/s00445-009-0313-7, 2010.

Kern, C., Deutschmann, T., Werner, C., Sutton, A. J., Elias, T., and Kelly, P. J.: Improving the accuracy of $\mathrm{SO}_{2}$ column densities and emission rates obtained from upward-looking UV-spectroscopic measurements of volcanic plumes by taking realistic radiative transfer into account, J. Geophys. Res.-Atmos., 117, D20302, doi:10.1029/2012JD017936, 2012.

Kraus, S.: DOASIS: A framework design for DOAS, Shaker, http: //books.google.no/books?id=GFF5AAAACAAJ (last access: 25 September 2014), 2006.

La Spina, A., Burton, M., and Salerno, G. G.: Unravelling the processes controlling gas emissions from the central and northeast craters of Mt. Etna, J. Volcanol. Geoth. Res., 198, 368-376, doi:10.1016/j.jvolgeores.2010.09.018, 2010.

Lee, C., Kim, Y. J., Tanimoto, H., Bobrowski, N., Platt, U., Mori, T., Yamamoto, K., and Hong, C. S.: High ClO and ozone depletion observed in the plume of Sakurajima volcano, Japan, Geophys. Res. Lett., 32, L21809, doi:10.1029/2005GL023785, 2005.

Lee, C., Martin, R. V., van Donkelaar, A., Lee, H., Dickerson, R. R., Hains, J. C., Krotkov, N., Richter, A., Vinnikov, K., and Schwab, J. J.: $\mathrm{SO}_{2}$ emissions and lifetimes: estimates from inverse modeling using in situ and global, space-based (SCIA-
MACHY and OMI) observations, J. Geophys. Res.-Atmos., 116, D06304, doi:10.1029/2010JD014758, 2011.

Lehrer, E., Wagenbach, D., and Platt, U.: Aerosol chemical composition during tropospheric ozone depletion at Ny Alesund/Svalbard, Tellus B, 49, 486-495, doi:10.1034/j.16000889.49.issue5.5.x, 1997.

Louban, I., Bobrowski, N., Rouwet, D., Inguaggiato, S., and Platt, U.: Imaging DOAS for volcanological applications, B. Volcanol., 71, 753-765, doi:10.1007/s00445-008-0262-6, 2009.

Lübcke, P., Bobrowski, N., Arellano, S., Galle, B., Garzón, G., Vogel, L., and Platt, $\mathrm{U} .: \mathrm{BrO} / \mathrm{SO}_{2}$ molar ratios from scanning DOAS measurements in the NOVAC network, Solid Earth, 5, 409-424, doi:10.5194/se-5-409-2014, 2014.

Martin, R., Mather, T., and Pyle, D.: High-temperature mixtures of magmatic and atmospheric gases, Geochem. Geophy. Geosy., 7, Q04006, doi:10.1029/2005GC001186, 2006.

Martin, R. S., Mather, T. A., Pyle, D. M., Power, M., Allen, A. G., Aiuppa, A., Horwell, C. J., and Ward, E. P. W.: Composition-resolved size distributions of volcanic aerosols in the Mt. Etna plumes, J. Geophys. Res.-Atmos., 113, D17211, doi:10.1029/2007JD009648, 2008.

Mayer, B. and Kylling, A.: Technical note: The libRadtran software package for radiative transfer calculations - description and examples of use, Atmos. Chem. Phys., 5, 1855-1877, doi:10.5194/acp-5-1855-2005, 2005.

McGonigle, A. J. S., Delmelle, P., Oppenheimer, C., Tsanev, V. I., Delfosse, T., Williams-Jones, G., Horton, K., and Mather, T. A.: $\mathrm{SO}_{2}$ depletion in tropospheric volcanic plumes, Geophys. Res. Lett., 31, L13201, doi:10.1029/2004GL019990, 2004.

Meller, R. and Moortgat, G.: Temperature dependence of the absorption cross sections of formaldehyde between 223 and $323 \mathrm{~K}$ in the wavelength range $225-375 \mathrm{~nm}$, J. Geophys. Res.-Atmos., 105, 7089-7101, doi:10.1029/1999JD901074, 2000.

Mori, T., Mori, T., Kazahaya, K., Ohwada, M., Hirabayashi, J., and Yoshikawa, S.: Effect of UV scattering on $\mathrm{SO} 2$ emission rate measurements, Geophys. Res. Lett., 33, L17315, doi:10.1029/2006GL026285, 2006.

Oppenheimer, C., Tsanev, V. I., Braban, C. F., Cox, R. A., Adams, J. W., Aiuppa, A., Bobrowski, N., Delmelle, P., Barclay, J., and McGonigle, A. J. S.: BrO formation in volcanic plumes, Geochim. Cosmochim. Ac., 70, 2935-2941, doi:10.1016/j.gca.2006.04.001, 2006.

Platt, U.: Reactive Halogen Species in the Mid-Latitude Troposphere - Recent Discoveries, Water Air Soil Poll., 123, 229-244, doi:10.1023/A:1005267321567, 2000.

Platt, U. and Janssen, C.: Observation and role of the free radicals $\mathrm{NO}_{3}, \mathrm{ClO}, \mathrm{BrO}$ and $\mathrm{IO}$ in the troposphere, Faraday Discuss., 100, 175-198, doi:10.1039/FD9950000175, 1995.

Platt, U. and Stutz, J.: Differential Optical Absorption Spectroscopy: Principles and Application, Springer, doi:10.1007/9783-540-75776-4, 2008.

Pyle, D. and Mather, T.: Halogens in igneous processes and their fluxes to the atmosphere and oceans from volcanic activity: a review, Chem. Geol., 263, 110-121, doi:10.1016/j.chemgeo.2008.11.013, 2009.

Roberts, T., Braban, C., Martin, R., Oppenheimer, C., Adams, J., Cox, R., Jones, R., and Griffiths, P.: Modelling reactive halogen formation and ozone depletion in volcanic plumes, Chem. Geol., 263, 151-163, doi:10.1029/JD095iD11p18577, 2009. 
Robock, A.: Volcanic eruptions and climate, Rev. Geophys., 38, 191-219, doi:10.1029/1998RG000054, 2000.

Sander, S. P., Friedl, R. R., Golden, D. M., Kurylo, M. J., Moortgat, G. K., Keller-Rudeck, H., Wine, P. H., Ravishankara, A. R., Kolb, C. E., Molina, M. J., Finlaysson-Pitts, B. J., Huie, R. E., and Orkin, R. L.: Chemical Kinetics and Photochemical Data for Use in Atmospheric Studies, Tech. Rep. Evaluation Number 15, JPL Publication, 06-2, Jet Propolsion Laboratory, NASA, available at: http://jpldataeval.jpl.nasa.gov/ (last access: 2 May 2015), 2006.

Schofield, R., Kreher, K., Connor, B. J., Johnston, P. V., Thomas, A., Shooter, D., Chipperfield, M. P., Rodgers, C. D., and Mount, G. H.: Retrieved tropospheric and stratospheric BrO columns over Lauder, New Zealand, J. Geophys. Res.-Atmos., 109, D14304, doi:10.1029/2003JD004463, 2004.

Simpson, W. R., von Glasow, R., Riedel, K., Anderson, P., Ariya, P., Bottenheim, J., Burrows, J., Carpenter, L. J., Frieß, U., Goodsite, M. E., Heard, D., Hutterli, M., Jacobi, H.-W., Kaleschke, L., Neff, B., Plane, J., Platt, U., Richter, A., Roscoe, H., Sander, R., Shepson, P., Sodeau, J., Steffen, A., Wagner, T., and Wolff, E.: Halogens and their role in polar boundary-layer ozone depletion, Atmos. Chem. Phys., 7, 4375-4418, doi:10.5194/acp-74375-2007, 2007.

Sinnhuber, B.- M., Rozanov, A., Sheode, N., Afe, O. T., Richter, A., Sinnhuber, M., Wittrock, F., Burrows, J. P., Stiller, G. P., von Clarmann, T., and Linden, A.: Global observations of stratospheric bromine monoxide from SCIAMACHY, Geophys. Res. Lett., 32, L20810, doi:10.1029/2005GL023839, 2005.

Spietz, P., Martín, J. C. G., and Burrows, J. P.: Spectroscopic studies of the I2/O3 photochemistry: Part 2. Improved spectra of iodine oxides and analysis of the IO absorption spectrum, J. Photoch. Photobio. A, 176, 50-67, doi:10.1016/j.jphotochem.2005.08.023, 2005.

Stutz, J. and Platt, U.: Numerical analysis and estimation of the statistical error of differential optical absorption spectroscopy measurements with least-squares methods, Appl. Opt., 35, 60416053, doi:10.1364/AO.35.006041, 1996.

Textor, C., Graf, H.-F., C., T., and Robock, A.: Emissions from volcanoes, in: Emissions of Atmospheric Trace Compounds, edited by: Granier, C., Artaxo, P., and Reeves, C., 269-303, Klewer, Dordrecht, Netherlands, doi:10.1007/978-1-4020-21671_7, 2004.

Theys, N., De Smedt, I., Van Roozendael, M., Froidevaux, L., Clarisse, L., and Hendrick, F.: First satellite detection of volcanic OClO after the eruption of Puyehue-Cordón Caulle, Geophys. Res. Lett., 41, 667-672, doi:10.1002/2013GL058416, 2014.
Turner, D. B.: Workbook of atmospheric dispersion estimates, Office of Air Programs Pub. No. AP-26, Enironmental Protection Agency, 1970.

Vogel, L.: Volcanic plumes: Evaluation of spectroscopic measurements, early detection and bromine chemistry, $\mathrm{PhD}$ thesis, Combined Faculties for the Natural Sciences and for Mathematics, Ruperto Carola University of Heidelberg, Germany, available at: http://archiv.ub.uni-heidelberg.de/volltextserver/13219/ (last access: 2 May 2015), 2011.

Vogel, L., Sihler, H., Lampel, J., Wagner, T., and Platt, U.: Retrieval interval mapping: a tool to visualize the impact of the spectral retrieval range on differential optical absorption spectroscopy evaluations, Atmos. Meas. Tech., 6, 275-299, doi:10.5194/amt6-275-2013, 2013.

Voigt, S., Orphal, J., and Burrows, J.: The temperature and pressure dependence of the absorption cross-sections of $\mathrm{NO}_{2}$ in the $250-800 \mathrm{~nm}$ region measured by Fourier-transform spectroscopy, J. Photoch. Photobio. A, 149, 1-7, doi:10.1016/S10106030(01)00650-5, 2002.

Voigt, C., Jessberger, P., Jurkat, T., Kaufmann, S., Baumann, R., Schlager, H., Bobrowski, N., Giuffrida, G., and Salerno, G.: Evolution of $\mathrm{CO}_{2}, \mathrm{SO}_{2}, \mathrm{HCl}$, and $\mathrm{HNO}_{3}$ in the volcanic plumes from Etna, Geophys. Res. Lett., 41, 2196-2203, doi:10.1002/2013GL058974, 2014

von Glasow, R.: Atmospheric chemistry in volcanic plumes, P. Natl. Acad. Sci. USA, 107, 6594-6599, doi:10.1073/pnas.0913164107, 2010.

von Glasow, R., Bobrowski, N., and Kern, C.: The effects of volcanic eruptions on atmospheric chemistry, Chem. Geol., 263, 131-142, doi:10.1016/j.chemgeo.2008.08.020, 2009.

Vountas, M., Roznaov, V., and Burrows, J.: Ring effect: Impact of rotational Raman scattering on radiative transfer in earth's atmosphere, J. Quant. Spectrosc. Ra., 60, 943-961, doi:10.1016/S0022-4073(97)00186-6, 1998.

Wagner, T., Beirle, S., and Deutschmann, T.: Three-dimensional simulation of the Ring effect in observations of scattered sun light using Monte Carlo radiative transfer models, Atmos. Meas. Tech., 2, 113-124, doi:10.5194/amt-2-113-2009, 2009.

Wennberg, P.: Atmospheric chemistry: bromine explosion, Nature, 397, 299-301, doi:10.1038/16805, 1999.

Wilmouth, D. M., Hanisco, T. F., Donahue, N. M., and Anderson, J. G.: Fourier transform ultraviolet spectroscopy of the $A^{2} \Pi_{(3 / 2)} \leftarrow X^{2} \Pi_{(3 / 2)}$ transition of BrO, J. Phys. Chem. A, 103, 8935-8945, doi:10.1021/jp991651o, 1999.

Wittmer, J., Bobrowski, N., Liotta, M., Giuffrida, G., Calabrese, S., and Platt, U.: Active alkaline traps to determine acidic-gas ratios in volcanic plumes: Sampling techniques and analytical methods, Geochem. Geophy. Geosy., 15, 2797-2820, doi:10.1002/2013GC005133, 2014. 